\title{
A new technique using the
} aero-infiltrometer to characterise the natural soils based on the measurements of infiltration rate and soil moisture content

M. A. Fulazzaky ${ }^{1}$, Z. Yusop ${ }^{1}$, I. Ibrahim ${ }^{2}$, and A. H. M. Kassim ${ }^{2}$

${ }^{1}$ Institute of Environmental and Water Resources Management, Water Research Alliance, Universiti Teknologi Malaysia, 81310 UTM Skudai, Johor Bahru, Malaysia

${ }^{2}$ Department of Water and Environment Engineering, Faculty of Civil and Environmental Engineering, Universiti Tun Hussein Onn Malaysia 86400 Parit Raja, Batu Pahat, Johor, Malaysia

Received: 6 February 2014 - Accepted: 7 February 2014 - Published: 28 February 2014 Correspondence to: M. A. Fulazzaky (fulazzaky@utm.my)

Published by Copernicus Publications on behalf of the European Geosciences Union.

A new technique

using the

aero-infiltrometer

M. A. Fulazzaky et al.

Title Page
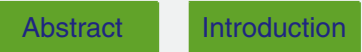

Conclusions

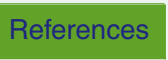

Tables

Figures

14

4

Back

Close

Full Screen / Esc

Printer-friendly Version

Interactive Discussion
$>$ 


\section{Abstract}

Infiltration rate $(f)$ and soil moisture content $(\theta)$ are the important factors for water resources management. Accurate measurements of these factors are not so readily available in most farmlands since present measuring equipments are not really 5 suitable. This paper proposes the measuring device that uses a simple method to measure the rate of water infiltration into the ground and to determine the percentage of water contained in the soil. The two empirical equations which formulated on the basis of power regression models of plotting $f$ vs. air pressure dropping rate $(P)$ and $\theta$ vs. $P$ are proposed to evaluate the dynamic properties of soil-water and soil-air interface from a three-phase system. All the parameters in equations have physical meanings, and experimental data validation shows that the equations are sufficiently accurate. Aero-infiltrometer was used to measure both the variations of $f$ and $\theta$ at three natural soil sites to contribute to operational water management issues and soil texture identification. In the future, new research opportunities on basic knowledge of 15 air diffusion into the ground will contribute to more versatile techniques in measurement of water infiltration.

\section{Introduction}

Infiltration as part of hydrologic cycle is the entry of waters into the ground due to gravity forces and initially controlled by capillary forces (Ravi and Williams, 1998), and the hydrologists also remarked it as opposite of seepage. Infiltration is the net movement of water into soil (Davis and Masten, 2004) and has a balance of rainfall from overland flow and evaporation. Rate and quantity of the water which infiltrates into the ground have a function of soil type, soil moisture, soil permeability, land cover, ground surface condition, depth of accumulated water table, as well as intensity and volume of precipitation (Wanielista, 1990) and thus need to be verified for multipurpose land use information. Soil type helps identify size and number of capillaries through
HESSD

$11,2515-2553,2014$

A new technique

using the

aero-infiltrometer

M. A. Fulazzaky et al.

Title Page

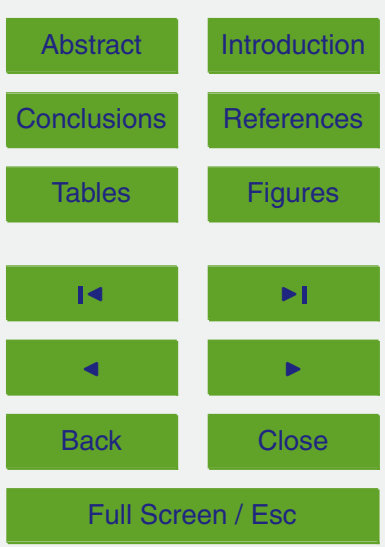

Printer-friendly Version

Interactive Discussion 
which water and air penetrate a vadose zone. Soil moisture content $(\theta)$ helps identify capillary potential and relative conductivity of soil. If the vadose zone has a low $\theta$, its capillary potential is high and its conductivity is low (Wanielista, 1990). Soil conductivity to transport a solute increases with $\theta$; heavy rainfall can increase $\theta$ (Xu et al., 2012). 5 Depth of groundwater table controls potential amount of water which can infiltrate and potential amount of air which can diffuse from the surface to subsurface land (Peyraube et al., 2012). High groundwater table means that potential infiltration volume is limited. Soil type with its water condition and intensity with volume of precipitation determine amount of water which from precipitation can actually infiltrate into the o ground (Wanielista, 1990).

Infiltrometer is a device to be used for measuring the rate of water infiltration into the ground and also to determine the water content of the soil. The single- or doublering infiltrometers are commonly used for measuring the infiltration rates $(f)$. The others are disc permeameter, tension infiltrometer, turf-tec infiltrometer, and sprinkler infiltrometer. There are several challenges related to the use of ring infiltrometers, i.e., (1) pounding of the infiltrometer into the ground deforms the soil, compressing it, or causing cracks which can affect the measured infiltration capacity, (2) with a singlering infiltrometer, water spreads laterally as well as vertically and thus the analysis is more difficult, and (3) ring infiltrometers cannot reliably characterise the infiltration of furrow irrigation, of sprinkler irrigation, or of rainfall (Bouwer, 1986). The double ring infiltrometer consists of an inner and outer ring inserted into the ground and is a way of measuring saturated hydraulic conductivity of the surface layer. Each ring could be supplied with a constant head of water. The measure of the $f$ value at a land location is determined by the depth of water that infiltrates into the soils per unit of time. Saturated hydraulic conductivity can be estimated for a soil when the rate of water flow in the inner ring is at a steady state condition (Mirus and Perkins, 2012). The use of water as dynamic vector is indispensable for measuring rate of water infiltration into the ground when using the ring infiltrometers or other classical infiltrometers but it cannot be easily found anywhere. For hydrologists, water engineers, farmers, and irrigators, both the

\section{HESSD}

A new technique using the

aero-infiltrometer

M. A. Fulazzaky et al.

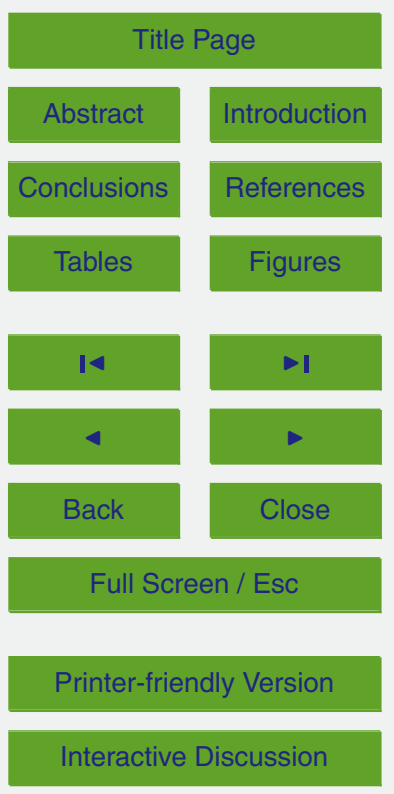


measurements of $f$ and $\theta$ are the important indications concerning the efficiency of irrigation and drainage, optimising the availability of water for plants, improving the yield of crops, and minimising erosion (Fulazzaky and Gany, 2009; Wang et al., 2012). The data of $f$ and $\theta$ collected especially from a region of high intensity land use are 5 very important for better water management. Unfortunately, the use of such as ring infiltrometer is sometimes difficult due to uncomfortable and unwieldy equipment and is also binding available water. This will be facing the problems of unfitting measurement at slanted lands of the mountain valleys and hilly areas. Mini disk infiltrometer (MDI) has been proposed as a quick way to test the unsaturated hydraulic conductivity and $10 f$, the experimental results showed that the hydraulic conductivity measured by MDI with a bubble chamber head control and larger disk diameter was less dependent on $\theta$, but more sensitive to inclination (Madsen and Chandler, 2007). A methodology that combines a simple falling-head small-diameter single-ring infiltrometer with analytical formulas for calculating field-saturated hydraulic conductivity permits individual field measurements to be obtained in a short time (Nimmo et al., 2009). The effort of extending the applicability of infiltrometric techniques using the Beerkan estimation of soil transfer parameters has been proposed to facilitate the determination of both the water retention curve and the hydraulic conductivity curve (Lassabatère et al., 2006). Still, an alternative measuring device that uses air as dynamic vector has an advantage and is expected to be more versatile techniques. Air diffusion process occurs in response to a pressure gradient. Air movement could take place from regions of higher pressure to regions of lower pressure. Air and water in the voids of a soil are the conducting media for diffusion processes (Fredlund et al., 2012). Aero-infiltrometer as a new hydrological device based on the measurement of the changes in air pressure drop $\left(L_{p}\right)$ over time would be useful to determine $f$ and then can be extended to determine $\theta$ (Fulazzaky et al., 2008, 2009a, b). Even though the deformation of soil inside the inner diameter pipe of air injection nozzle may occur during the installation of this device into the ground, the nozzle inserted with compression fittings has no effect on soil physical properties below such hydrological equipment installed. Therefore, the
HESSD

A new technique using the aero-infiltrometer

M. A. Fulazzaky et al.

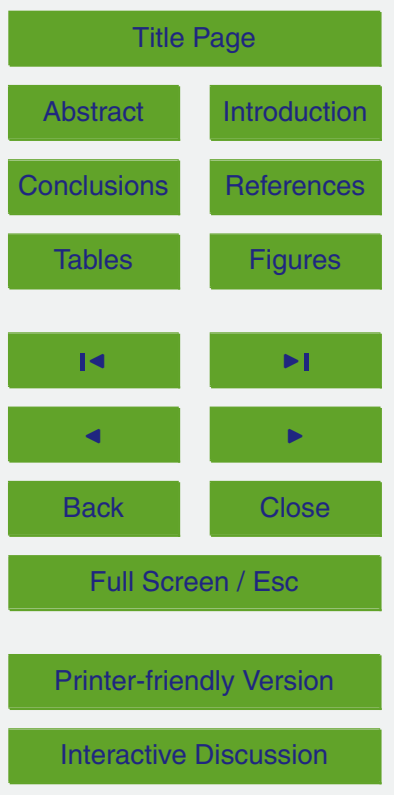


use of aero-infiltrometer should be further promoted as an important device for rapid field determination of either $f$ or $\theta$.

A study on two-phase flow equations accounting for air entrapment effects showed that air compression ahead of the wetting front is a major cause of wetting front 5 instability followed by fingering and may affect the change in $f$ significantly (Wang et al., 1997). The mathematical equations derived on the Green-Ampt assumptions basis were extended to include the potential effects of air compression and air counter-flow during the water infiltrates into subsurface land (Wang et al., 1997). A model of air-water system by van Genuchten (1980) has already tried to derive 10 a functional correlation between capillary pressure and saturation of the soil and extended by Ippisch et al. (2006), Kutlu and Ersahin (2008), Han et al. (2010), Liu et al. (2011), Valiantzas (2011) and Liu and Xie (2013) in analytical determination of some parameters related to soil science. The initial- $\theta$ has a considerable influence on the resulting structure and aggregation of such as clayey soils and can affect the rate of air diffusion into the ground (Allaire et al., 2008; Davidson and Trumbore, 1995). Still the dynamic and hydraulic circumstances of air diffusion into the ground including the establishment of the correlation plots $f$ vs. air pressure dropping rate $(P)$ or $\theta$ vs. $P$ are not fully understood. The objectives of this study are: (1) to propose a new measuring device which is feasible to be used for both the measurements of $20 f$ and $\theta,(2)$ to formulate the empirical equations based on the data of the natural soils experiment from the aero-infiltrometer and double-ring infiltrometer, and (3) to analyse physical interpretations of the parameters in equations originally reading from the field natural soil experiments supporting with complementary artificial soil data of the laboratory tests for quantitatively characterising the textural features and spatial variability of saturated hydraulic conductivity for different soil types.

HESSD

$11,2515-2553,2014$

A new technique

using the

aero-infiltrometer

M. A. Fulazzaky et al.

Title Page

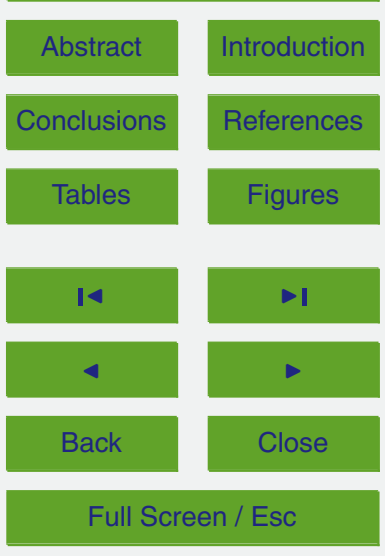

Printer-friendly Version

Interactive Discussion 


\section{Materials and methods}

\subsection{Aero-infiltrometer and measurement procedure}

The aero-infiltrometer consists of air tank with $60 \mathrm{~cm}$ length and $5 \mathrm{~cm}$ diameter, valve, air injection nozzle with a diameter of $2 \mathrm{~cm}$, air input nozzle, and pressure meter, as

5 shown in Fig. 1 (Fulazzaky et al., 2008, 2009a, b). The different diameters of the PVC pipe were designed conical from the air tank to air injection nozzle. The use of PVC pipe to invent this device is helpful due to flexible plastic property and low price comparing the other materials of such as glass and steel. The advantages of PVC's aero-infiltrometer are easy to be assembled manually and have the ability to form a sharp edge of air injection nozzle for easily sticking into the ground.

The procedure used to collect the data from an aero-infiltrometer will vary depending on typical design, associated instruments, and type of materials. Figure 2 shows flowchart of the aero-infiltrometer test. Notes that: (1) a depth of $6 \mathrm{~cm}$ is sufficiently accurate to minimise deformation of the soil below the aero-infiltrometer installed; if air can flow in one-dimension at steady state condition, and a unit gradient is present in the underlying soil, the rate of air diffusion into the ground is approximately equal to the saturated air diffusion conductivity. The inner wall of the air injection nozzle provides like air jacket to diffuse air from the surface to subsurface land and is analogous to inner tube functioning of a double-ring infiltrometer when water infiltrates, because both have a function for controlling the laminar flow of fluid through the soils, and (2) the aims of fitting the $117 \mathrm{kPa}$ air pressure are to avoid instability of initial measurement, which can influence the accuracy of the results if air pressure injected is higher than $117 \mathrm{kPa}$, and to maximise the reading of air pressure drop, which probably affects the lack of the results if the pressure is lower than $117 \mathrm{kPa}$.

25 The spatial variability of saturated hydraulic conductivity in soils has a wide range of several orders of magnitude depending on the soil material (Abdulkadir et al., 2012) and can influence the results. The main consideration of this study is that the measurement should be sufficiently reliable and is necessary to be avoided from

A new technique using the aero-infiltrometer

M. A. Fulazzaky et al.

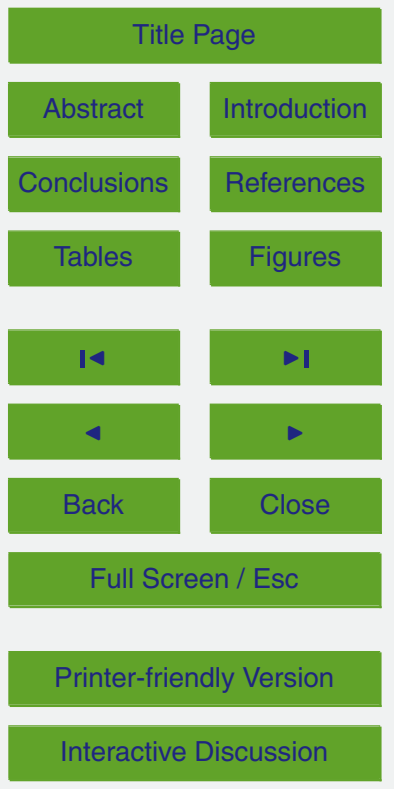


any risks of such soil deformation which may lead to inaccurate data. Therefore, at each location, the measurement of decreasing water level $\left(L_{w}\right)$ using the double-ring infiltrometer was carried out at the same soil type near the measurement of $L_{p}$ using the aero-infiltrometer with a distance of about one meter, which can represent identical soil conditions, and the data obtained from these measurements should be independent of each other. Detailed information of the soil characteristics i.e., texture, bulk density, and initial- $\theta$ can be performed based on the data measured air diffusion for further assessment. The double-ring infiltrometer used to measure $L_{\mathrm{w}}$ has an inner ring of $30 \mathrm{~cm}$ and outer ring of $53 \mathrm{~cm}$ with a depth of insertion of $6 \mathrm{~cm}$ and a height ponded 10 water of $10 \mathrm{~cm}$. The decrease in $L_{w}$ was measured in the inner ring while a pool of water was maintained at approximately the same level in the outer ring to reduce the amount of lateral flow from the inner ring. The decrease in $L_{w}$ in the inner ring was recorded at $1,5,10,15,20,25,30$ and $35 \mathrm{~min}$ and at $30 \mathrm{~min}$ intervals thereafter. For the first time, both the measurements of $L_{w}$ and $L_{p}$ at the same time are necessary for calibration and validation of the models. The use of the aero-infiltrometer can then be used solely for the measurements of $f$ and $\theta$ if the models have been validated. This offers some advantages because of the experimental practices can reduce deformation and compression of the soil to have wide applications in many types of land use.

\subsection{Establishment of the empirical equations}

\subsubsection{Background}

Aero-infiltrometer is feasible to be used for measuring $f$ and $\theta$ since the typical equations which correlate contingency of air diffusion to water infiltration into the ground have been established for a natural soil site. In order to establish the empirical models, the following assumptions were made that: (1) water and air are the dynamic vectors, (2) with pressure, air diffuses into the ground and moves from the land surface to subsurface, and (3) air movement is analogous to water movement into the ground. Even the circumstances of air-confining vadose zone such as air pressure

\section{HESSD}

11, 2515-2553, 2014

A new technique

using the

aero-infiltrometer

M. A. Fulazzaky et al.

Title Page

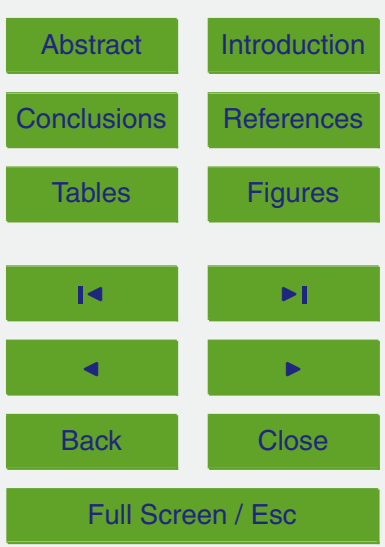

Printer-friendly Version

Interactive Discussion 
fluctuation, air eruptions from surface, hysteresis in capillary pressure, and macroporous infiltration affect the rate of water infiltration into the soil (Wang et al., 1997), having a general equation can be useful for determining the variations of $f$ and $\theta$ accounting for all these circumstances. The equations to analyse air diffusion into 5 the ground and underground flows have been proposed by Petersen et al. (1994), Bartelt-Hunt and Smith (2002), Althaus et al. (2009) and Aharmouch and Amaziane (2012). Still the application of these equations for natural soils that have heterogeneous structures and erratic particle-size is insufficiently reliable. Dynamic and hydraulic properties of the soil are dependent on the capillary forces and vadose zone components of a three-phase system and thus control air diffusion and water infiltration into the ground. In this study, the empirical equations are able to be formulated considering the most fundamental aspects that both the variations of $P$ and $f$ have the decreasing trends pursuant to the test time $(t)$.

\subsubsection{Data calibration and equations}

State of soil can be described considering five soil-forming factors, i.e., parent material, topography, climate, biological activity, and time, which can determine soil drainage characteristics. More than 3000 specially named the soil types were recorded (Wanielista, 1990). Simplified approaches to determine $f$ of a soil including the empirical models proposed by Kostiakov (1932) and Horton (1939) use $t$ for 20 the variable. This study used the aero-infiltrometer to monitor $L_{p}$ and double-ring infiltrometer to monitor $L_{w}$ pursuant to $t$. The results of monitoring $L_{p}, L_{w}$ and $t$ were used as the data entry in determining the variations of $f$ and $\theta$ of the soils. The limitation of this study is the experimental sites conducted on soft clayey soil that influenced the interpretation of the results of more heterogeneous soil types. Data collected from the 25 three natural soil sites around the Universiti Tun Hussein Onn Malaysia campus and supporting by the data of laboratory tests for the artificial sandy clay (50\% sand; $50 \%$ clay) were used to describe the below ground and surface processes that involve the dynamics of air and water movement from the land surface to subsurface.
HESSD

$11,2515-2553,2014$

A new technique

using the

aero-infiltrometer

M. A. Fulazzaky et al.

Title Page

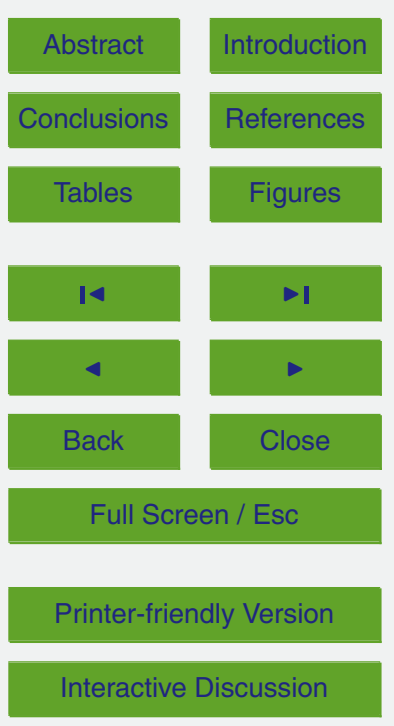


As starting point to establish the empirical equations that the variable $t$ data (see Table 1) reading from the aero-infiltrometer (Column 1) and double-ring infiltrometer (Column 3) were inserted into one column (Column 5) of cumulative $t$ (Cum.t). The following calibrations (Fig. 3) were made that: (1) both the interpolation and 5 extrapolation can be performed to avoid lack of the cumulative $L_{p}$ (Cum. $L_{p}$ ) data (Column 6), having the correlation plots the Cum. $L_{p}$ vs. Cum.t, and (2) the interpolation can be performed to avoid lack of the cumulative $L_{\mathrm{w}}\left(\right.$ Cum. $L_{\mathrm{w}}$ ) data (Column 7$)$, having the correlation plots Cum. $L_{\mathrm{w}}$ vs. Cum.t.

By definition, $P$ is the decrease in $L_{p}$ per unit $t$, this may be expressed in calculus

$P=\frac{\mathrm{d} L_{\mathrm{p}}}{\mathrm{d} t}$

where $P$ is air pressure dropping rate (in $\mathrm{kPah}^{-1}$ ), $\mathrm{d} L_{\mathrm{p}}$ is the change in $L_{\mathrm{p}}$ during $\mathrm{d} t$ (in $\mathrm{kPa}$ ), and $\mathrm{d} t$ is change of the test time (in $\mathrm{h}$ ).

One of the oldest and most widely used infiltration equations today was developed by Horton (1939). This equation assumes that rainfall intensity is greater than infiltration capacity at all times and $f$ decreases as $t$ increases (Bedient and Huber, 1992). The Horton equation's major drawback is that it does not consider storage available in the soil after varying amounts of the infiltration have occurred, but only considers infiltration as a function of $t$ (Akan, 1993). In this study, a simplified equation used to determine the experimental $f\left(f_{\text {exp }}\right)$ is defined as:

$f_{\exp }=\frac{\mathrm{d} L_{\mathrm{w}}}{\mathrm{d} t}$

where $f_{\text {exp }}$ is experimental infiltration rate $\left(\mathrm{cm} \mathrm{h}^{-1}\right), \mathrm{d} L_{\mathrm{w}}$ is the change in $L_{\mathrm{w}}$ during $\mathrm{d} t$ (in $\mathrm{cm}$ ), and $\mathrm{d} t$ is change of the test time (in $\mathrm{h}$ ).

In a stepwise model evaluation strategy, optimum parameters and their sensitivity are identified using calibration and global variance-based sensitivity analysis (Hartmann 2523
HESSD

11, 2515-2553, 2014

A new technique

using the

aero-infiltrometer

M. A. Fulazzaky et al.

Title Page

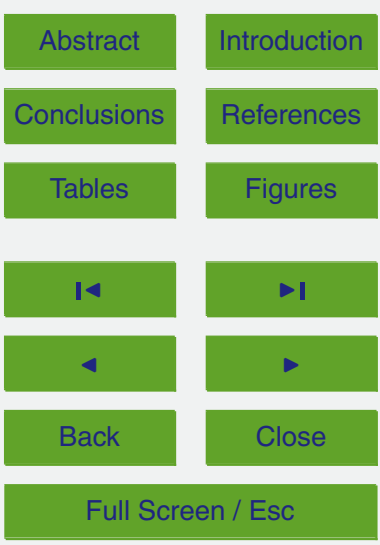

Printer-friendly Version

Interactive Discussion 
et al., 2013). The calibration (Column 5) of Cum.t accounting for air diffusion affects to intractable infiltration equation. In keeping with the serial data (see Table 1) of Cum. $L_{p}$ and Cum. $L_{\mathrm{w}}$ original from field experiments plus inter/extrapolation which have been gathered together (Columns 6-7) were useful for the calculations (Columns 8-9) of $P$ 5 and $f_{\text {exp }}$, respectively. A plot (Fig. 4) of $P$ vs. $f_{\exp }$ was rationalised through regression analysis to possess the ability to have a proper formula. The property of equation was selected only the best $R^{2}$ from trial amongst the linear, logarithmic, exponential, and power regressions. Accordingly, the power regression analysis has a good correlation for all the experiments $\left(R^{2}>0.907\right.$, see Table 2$)$. This determines the power regression 10 model to represent the data and gives a mathematical expression,

$f_{\text {th }}=\alpha \cdot P^{\beta}$

where $f_{\text {th }}$ is theoretical infiltration rate (in $\mathrm{cm} \mathrm{h}^{-1}$ ), $P$ is air pressure dropping rate (in $\left.\mathrm{kPah}^{-1}\right), \alpha$ is air diffusion coefficient depended on depth of air movement into the ground per unit of pressure (in $\mathrm{cm} \mathrm{kPa}^{-1}$ ), and $\beta$ is diffusion index depended on size and number of capillaries through which air moves from the surface to subsurface land (dimensionless).

Using Eq. (3) permits us to calculate $f_{\text {th }}$ if the parameters $\alpha$ and $\beta$ as well as the values $P$ were verified for a soil. The infiltration begins at some rates for initial infiltration and exponentially decreases until it reaches a constant rate when soil's porosity is at saturation (Horton, 1939). The variations (Fig. 5) of $f_{\text {th }}$ and $f_{\exp }$ recorded for each soil site show a similar trend over time. As an example, the $f_{\text {th }}$ values calculated using Eq. (3) (Column 10) are close to the $f_{\text {exp }}$ values calculated using Eq. (2) (Column 9) for site-1, as shown in Table 1. The empirical equation can be further solved with the natural and pseudo-soil experimentation functions in analysing the dynamic and hydraulic properties of the soil, over this part $\alpha$ indicates the depth of air movement into the ground per unit of pressure and $\beta$ relates to pore-size distribution and capillary number of the soil through which air flows into the subsurface land. Power regression

\section{HESSD}

$11,2515-2553,2014$

A new technique

using the

aero-infiltrometer

M. A. Fulazzaky et al.

Title Page

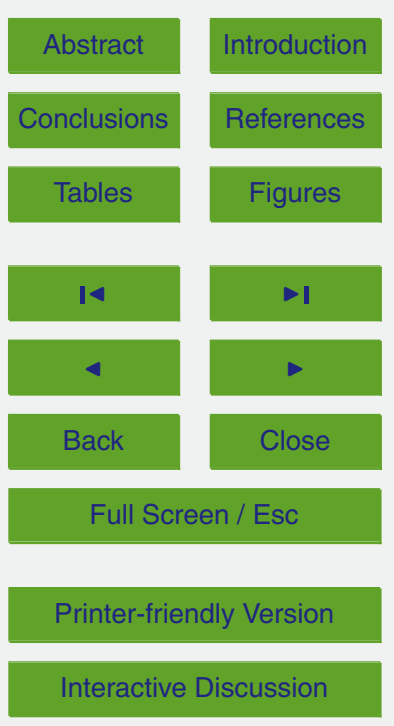


analysis provides an insight that leads to a better understanding the physical meanings of parameters $\alpha$ and $\beta$ in Eq. (3).

Water infiltration governed by soil sorptivity is a dynamic process of transient liquid displacement. At a steady state condition, the infiltration rate is assumed 5 equal to the saturated hydraulic conductivity (Novák et al., 2011). Saturated hydraulic conductivity depends more strongly on bulk density, organic carbon content, and land use (Jarvis et al., 2013). The effects of soil sorptivity decrease with time, and the final $f$ asymptotically approaches the saturated hydraulic conductivity of the soil (Diamond and Shanley, 2003; Reynolds et al., 2002). The movement of water and air in a vadose 10 zone is studied within soil physics and hydrology particularly hydrogeology and is of importance to agriculture, contaminant transport, and flood control. Water flows in a vadose zone are often described using the Richard's equation, which partially derived from Darcy's law (Kumar, 2004). Part of the voids in soil is occupied by water and the remainder by air. Rainfall flows through a vadose zone are the primary sources of recharge for aquifer. If the vadose zone envelops soil, the water contained therein is termed soil moisture. Since $\theta$ is defined as quantity of the water contained in soil, the portion of the soil volume occupied by water is measured by $\theta$. This property is used to a wide range in scientific and technical areas and is expressed as ratio of the water volume contained in soil, comparing the total volume of vadose zone. Theoretically, the value of $\theta$ can range from $0 \%$ when a soil is completely dry to $100 \%$ when a soil is fully saturated (van Genuchten, 1980; Dingman, 2002; Lawrence and Hornberger, 2007). In calculus this may be written,

$\theta_{\text {exp }}=\frac{\Delta \text { Cum. } L_{\mathrm{w}}}{\Delta \text { Cum. } L_{\mathrm{wc}}} \cdot 100 \%$

25 where $\theta_{\exp }$ is experimental soil moisture content (in \%), $\Delta$ Cum. $L_{w}$ is cumulative water infiltration during $\Delta t$ (in $\mathrm{cm}$ ), $\Delta$ Cum. $L_{\text {wc }}$ is cumulative water infiltration after achieving at its saturation (in $\mathrm{cm}$ ).

It seems that Eq. (4) remains workable due the decrease in water level as shown in Table 1 is equal to zero when the degree of saturation has reached at $100 \%$. The

A new technique using the aero-infiltrometer

M. A. Fulazzaky et al.

Title Page

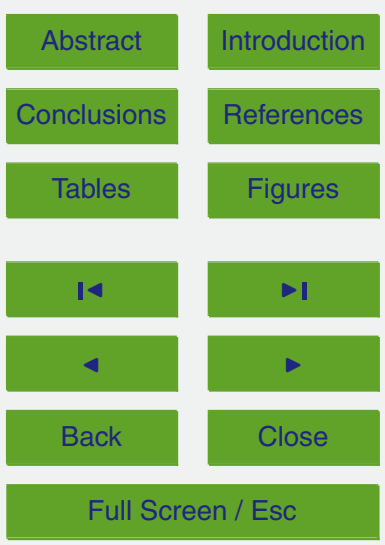

Printer-friendly Version

Interactive Discussion 
rate of air diffusion into the ground depends on capillarity and therefore soil texture, depth to water table, and $\theta$; however, air diffusion occurs most rapidly with increasing depth to the water table to a critical depth below which groundwater is not involved in the diffusion process (Kyrke-Smith et al., 2014). With a critical depth of the water 5 table, the process of air diffusion into the ground is effectively controlled by $\theta$ (Ma et al., 2013). The relationship between $P$ and $\theta$ could be a subject of this study since the measurements of $L_{p}$ and $L_{w}$ were performed independently at the soils with similar characteristics. Having a serial Cum. $L_{p}$ and Cum. $L_{w}$ dataset is able using Eq. (1) to calculate $P$ and using Eq. (4) to calculate $\theta_{\text {exp }}$. Accordingly, Fig. 6 shows the resulting 10 plots $P$ vs. $\theta_{\exp }$ and gives the following equation that:

$\theta_{\mathrm{th}}=\varepsilon \cdot P^{\gamma}$

where $\theta_{\text {th }}$ is theoretically soil moisture content (in \%), $P$ is air pressure dropping rate (in $\mathrm{kPah}^{-1}$ ), $\varepsilon$ is soil-air matrix potential coefficient depended on continuous-time to 15 saturate air into the ground per unit of pressure (in $\% \mathrm{~h}^{-1} \mathrm{kPa}^{-1}$ ), and $\gamma$ is air-filled porosity index related to capillary potential and relative conductivity (dimensionless).

The use of power regression model $\left(R^{2}>0.982\right.$, see Table 2$)$ is able to analyse the correlation between $\theta_{\exp }$ and $P$. Using Eq. (5) permits to calculate $\theta_{\text {th }}$ if the parameters $\varepsilon$ and $\gamma$ as well as the values $P$ were verified for a soil. As an example for site-1, 20 the values of $\theta_{\text {th }}$ calculated using Eq. (5) (Column 12) on the basis of depending on the measurements of $L_{p}$ are close to the values of $\theta_{\exp }$ calculated using Eq. (4) (Column 11) on the basis of depending on the measurements of $L_{w}$, as shown in Table 1. The variations (Fig. 5) of $\theta_{\text {th }}$ and $\theta_{\text {exp }}$ pursuant to $t$ show the adjacent trends to recording every site. If the $f$ value decreases toward a constant, the $\theta$ value can 25 reach up to $100 \%$ (at its saturation). Water flows into the ground depend on many factors, which can influence the movement of air in a soil, such as void spaces: porosity and resistance and conductive ways: permeability (Wanielista et al., 1997). Physical interpretation of the parameters $\varepsilon$ and $\gamma$ has an intuitive understanding of the time limitation period for air diffusion into the ground and is dependent on capillary potential 2526

\section{HESSD}

$11,2515-2553,2014$

A new technique

using the

aero-infiltrometer

M. A. Fulazzaky et al.

Title Page

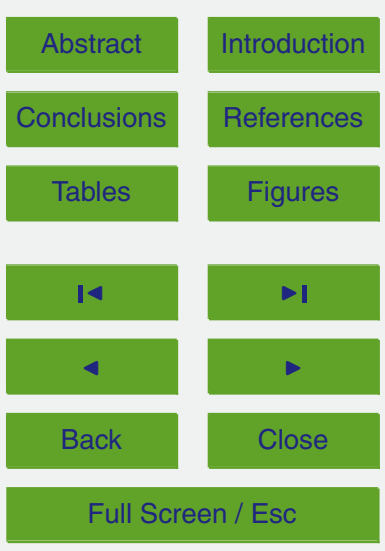

Printer-friendly Version

Interactive Discussion 
and continuity of void spaces in soils. The adjacent trends (Fig. 5) in curves $f_{\text {th }}$ and $f_{\text {exp }}$ as well as in curves $\theta_{\text {th }}$ and $\theta_{\text {exp }}$ pursuant to $t$ make a convincing argument that the use of aero-infiltrometer in measuring of $f$ and $\theta$ is feasible. Time range of collecting data $t$ and $L_{p}$ from aero-infiltrometer is faster than that of collecting data $t$ and $L_{\mathrm{w}}$ from 5 double-ring infiltrometer. Still, the extrapolation can be performed to avoid lack of the $L_{p}$ data since the parameters $\alpha, \beta, \varepsilon$ and $\gamma$ have been verified for a soil.

\section{Results and discussion}

\subsection{Typical air pressure dropping rate for the natural soils}

It is recognized that $P$ is rate of air diffusion from the surface to subsurface land caused 10 by air pressure and can be calculated using Eq. (1). The results (Figs. 4 and 6) showed that the values of $P$ ranged from 59 to $443 \mathrm{kPah}^{-1}$ for the natural soil of site-1, from 461 to $1733 \mathrm{kPah}^{-1}$ for that of site-2, and from 50 to $414 \mathrm{kPah}^{-1}$ for that of site-3. Supposing the variant $P$ is dependent on type and characteristics of the soil. Thus typical $P$ value may typify the classification of the soil and is controlled by size, shape, and void spaces continuity, which in turn depends on bulk density, structure, and texture of the soil. Accordingly, the ability of air movement from the land surface to subsurface is dependent on permeability and capillary potential of the soil.

\subsection{Classification of the soils typified by infiltration rate and soil moisture content}

20 Normal non-compacted soils such as grassland have been classified into six textures, i.e., coarse, moderately coarse, medium, moderately fine, fine, and very fine (Brady and Weil, 2002). Each classification was named in accordance with the ability of water infiltration into the ground. Even though $f$ depending on dynamic soil properties could be particularly affected by initial- $\theta$, the reasonable transient $f_{\text {th }}$ values can be used

A new technique

using the

aero-infiltrometer

M. A. Fulazzaky et al.

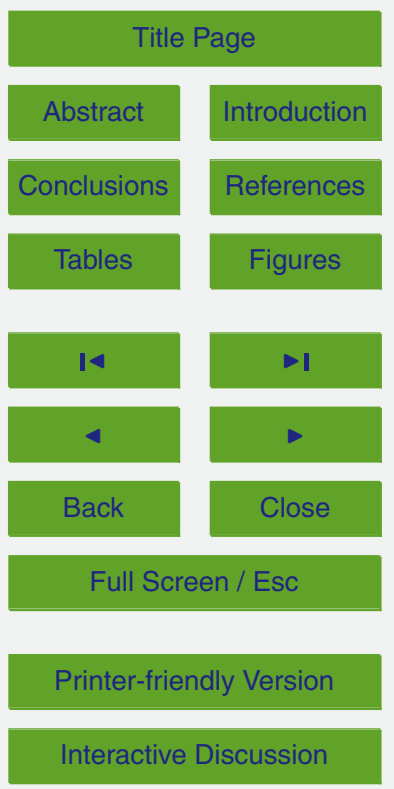


site locations of the natural soil; however, each site location has a different spatialtemporal variability. Still, the results obtained show a data trend that is able of tracing the empirical evidence for both the $f_{\exp }$ and $f_{\text {th }}$ curves (see Fig. 5). Moreover, the typical behaviours of soil influenced by initial- $\theta$ might be further discussed and validated with 5 the artificial soil tests. The following suggestions to classify type and texture of the soils tested were made based on the literatures by Hillel (1980), Kopec (1995) and Brady and Weil (2002), such that: (1) a gravel coarse sand for the natural soil of site-1 is typified by $f$ ranged from 4.1 to $80.6 \mathrm{~cm} \mathrm{~h}^{-1}$ and is classified into coarse texture, (2) a very fine sandy loam for that of site-2 is typified by $f$ ranged from 2.0 to $6.3 \mathrm{~cm} \mathrm{~h}^{-1}$

10 and is classified into medium texture, and (3) a sand loamy sand for that of site-3 is typified by $f$ ranged from 11.8 to $40.2 \mathrm{~cm} \mathrm{~h}^{-1}$ and is classified into coarse texture. Both the variations (Table 1 ) of $P$ and $f_{\text {exp }}$ show a decreasing trend with increased Cum.t and might correlate consistently with each other. Figure 4 shows the resulting plots $P$ vs. $f_{\text {exp }}$ that gives a model-based assessment of Eq. (3) for water infiltration. 15 Correlation for Eq. (3) is good $\left(R^{2}>0.907\right.$, see Table 2) and hence using Eq. (3) permits us to calculate $t_{\text {th }}$. Figure 5 shows the adjacent curves in the variations of $f_{\text {th }}$ and $f_{\text {exp }}$ pursuant to $t$, meaning that air diffusion into the ground can be further proposed for classifying the type and texture of the soils. The following suggestions were made: (1) coarse-textured gravel coarse sand (site-1) is typified by $P$ ranged 20 from 59 to $443 \mathrm{kPah}^{-1}$, (2) medium-textured very fine sandy loam (site-2) is typified by $P$ ranged from 461 to $1733 \mathrm{kPah}^{-1}$, and (3) coarse-textured sand loamy sand (site-3) is typified by $P$ ranged from 50 to $414 \mathrm{kPah}^{-1}$. Evidence shows that some inconsistencies between $f$ and $P$ could have a good scientific explanation, because the behaviours of air diffusion might be different from those of water infiltration into the ground. Both the variations of $P$ and $f$ with $t$ are dependent on pore-size distribution and capillary number of the soil. Even though the theoretical explanation is quite difficult to differentiate the behavioural soils regarding the correlation between air diffusion and water infiltration into the ground, the empirical equations were built on the basis of both the variations of $P$ and $f$ have a decreasing trend over $t$. Physical interpretation for

\section{HESSD}

11, 2515-2553, 2014

A new technique

using the

aero-infiltrometer

M. A. Fulazzaky et al.

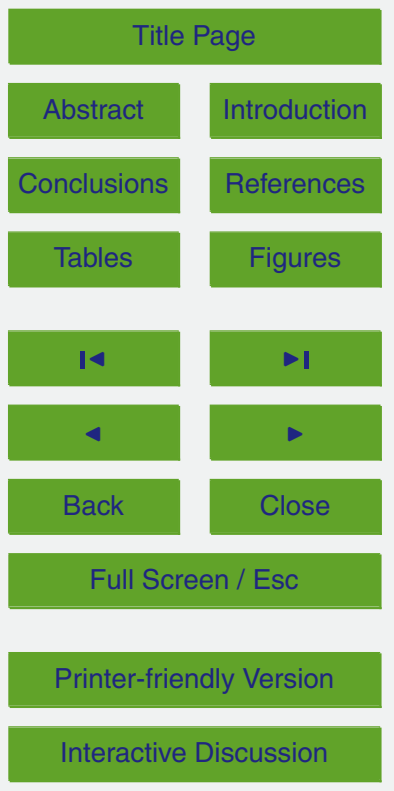


parameters $\alpha$ and $\beta$ in Eq. (3) can be analysed considering depth of air movement per unit of pressure and thus depends on structure and texture of the soil.

Soil specific initial- $\theta$ is dependent on spatial-temporal change and controlled by its structure and texture. There are many complexities associated with a vadose zone 5 because of its fissured and fractured nature. Figure 5 shows the adjacent curves for the variations of $\theta_{\text {th }}$ and $\theta_{\exp }$ with $t$. To describe the curves meander of the figure, the following suggestions were made: (1) coarse-textured gravel coarse sand (site1) has a $\theta$ ranged from 21.8 to $100 \%$, (2) medium-textured very fine sandy loam (site-2) has a $\theta$ ranged from 1.0 to $100 \%$, and (3) coarse-textured sand loamy sand 10 (site-3) has a $\theta$ ranged from 3.5 to $100 \%$. The data trends (Table 1 ) show that $P$ decreases, but on the contrary, $\theta_{\text {exp }}$ increases as Cum.t increases. Figure 6 plots $P$ vs. $\theta_{\text {exp }}$ that gives a power model of Eq. (5), which can be used to calculate $\theta_{\text {th }}$ on the basis of data of air diffusion into the ground. Correlation for Eq. (5) is a good $\left(R^{2}>0.982\right.$, see Table 2). Physical interpretation for parameters $\varepsilon$ and $\gamma$ in

15 Eq. (5) may be analysed accounting for continuous-time of air movement per unit of pressure, depending on dynamic and hydraulic properties of the soil. We suppose that the decrease in $P$ with increasing of air pressure in vadose zone is dependent on both the capillary potential and relative conductivity of the soil. Interpretation for the correlation between $f$ and $P$ as well as that between $\theta$ and $P$ helps identify dynamic and

20 hydraulic circumstances of the soil and might confirm a simple approach to describe the capillary pressure-saturation behaviour of a three-phase system by a combination of the capillary pressure-saturation functions of two-phase system (van Genuchten, 1980).

\subsection{Soil characteristics, air diffusion, and infiltration rate}

25 Soil type and degree of soil saturation are the major determining factors of infiltration. Soil is made up of an extensive variety of substances, minerals, and rocks. The components composing of a vadose zone can be classified into four groups i.e., minerals, organic matter, air, and water. The major components of soil are minerals

A new technique using the aero-infiltrometer

M. A. Fulazzaky et al.

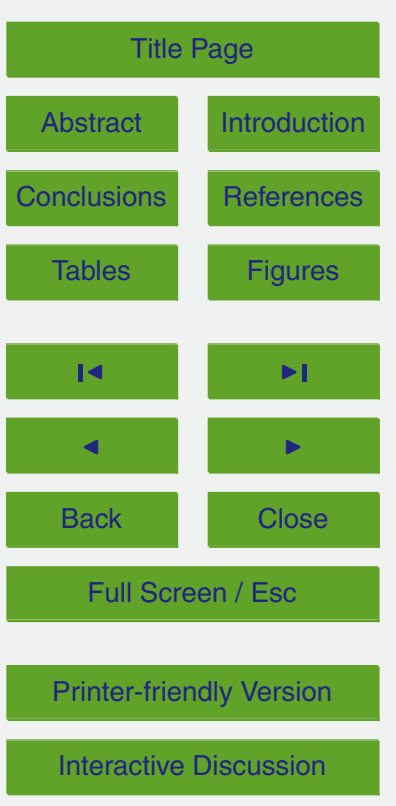


(sand, silt, clay) and organic matter, which can form its specific texture and structure by which control air and water flow through a vadose zone. In this study, the parameter $\alpha$ in Eq. (3) helps identify the depth of air diffusion into the ground per unit of pressure and is dependent on air pressure as well as the physical and hydraulic properties of 5 the soil. The parameter $\beta$ in Eq. (3) is dependent on pore-size distribution and capillary number of the soil. Accordingly, each shape of the curve $f_{\text {th }}=\alpha \cdot P^{\beta}$ (see Fig. 4) has a specific inclination to differentiate soil families from each other. Both the variants $\alpha$ and $\beta$ could be used to interpret the properties of soil. The laboratory test data were conducted to validate that hypothesis made of using parameter $\alpha$ and $\beta$ to interpret the 10 properties of the natural soils is still reliable. It appears that this study does not take into account statistical analysis due to time as variable is of the major issues in conducting this research study; however, the use of power models to follow trends in field and laboratory data is useful for reasonable descriptions including the conclusion drawn based on the data of parameters $\alpha$ and $\beta$ presented in this manuscript. An analysis of the continuous-time gives insights on dynamic and hydraulic properties of the soil, such that: (1) water infiltration into the gravel coarse sand (site-1) is faster than that into the sand loamy sand (site-3) and then than that into the very fine sandy loam (sites2), while (2) air diffusion into the very fine sandy loam (site-2) is faster than that into the gravel coarse sand (site-1) and then than that into the sand loamy sand (site-3).

The movements of air and water are dependent on both the texture and structure of the soil. Large continuous pores of textured coarse permit a rapid water movement through the gravel coarse sand (site-1) and the sand loamy sand (site-3) due to coarse-textured properties of having a greater surface roughness are advantageous to water movement (Brady and Weil, 2002). Due to porous medium properties often resulting in abrupt transitions, the less permeable very fine sandy loam (sites-2) that has a fine pore-size distribution and large capillary numbers is more suitable for air movement. According to Eq. (3), $\alpha$ is defined as air diffusion coefficient depended on depth of air movement into the ground per unit of pressure and thus the variant $\alpha$ may typify the depth of air movement into the ground. Therefore, air diffusion into the sand loamy sand should be
HESSD

A new technique using the aero-infiltrometer

M. A. Fulazzaky et al.

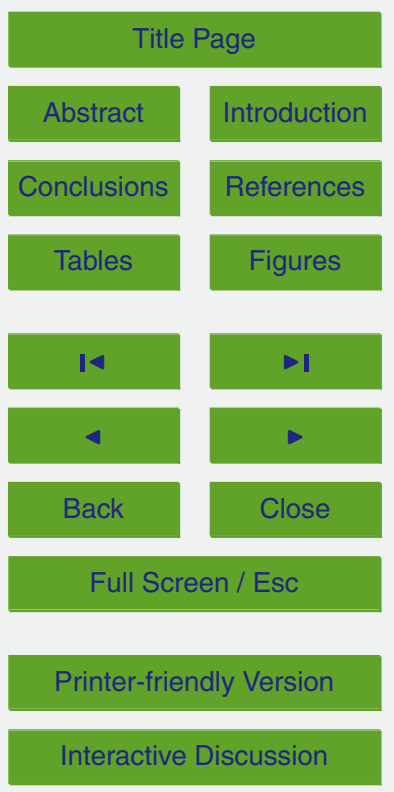


deeper than that into the very fine sandy loam and then than that into the gravel coarse sand as the $\alpha$ values of $1.886,0.014$ and $0.009 \mathrm{~cm} \mathrm{kPa}^{-1}$, respectively, were verified (see Table 3). The different shapes in Fig. 4 would be affected by texture and structure of the soil and can be used to characterise the movement of fluid (air or water) into the 5 ground. It appears that a low $\alpha$ value of $0.009 \mathrm{~cm} \mathrm{kPa}^{-1}$ may be inconsistent for coarsetextured soil of site-1, it is because of $P$ to move air from the air tank to gravel coarse sand is low due to low pressure gradient force caused by a high initial- $\theta$ of $21.8 \%$ could affect the dynamic interaction between air in and above the soil. Air contained within a very fine sandy loam has a relatively low pressure due to air conjunction from the 10 atmosphere is difficult. With this experiment, air can move easily from the air tank to subsurface land as the pressure gradient is high. As a consequence, air movement into the medium-textured soil is fast enough for air penetration and controlled by its capillary forces consisting of pore-size distribution and number of capillaries. Even if the value $f$ soil test for the coarse-textured soils was high as compared to the medium-textured 15 soil, the rate of water flow from the double-ring infiltrometer could relate to high rainfall intensity of greater than $f$ and is valid to have a reasonable model. Therefore, even the $f$ model in Fig. 7 looks like the Horton's equation, indicating that $f$ decreases with $t$. Still the trend in curve $f_{\text {th }}=\alpha \cdot P^{\beta}$ modelling for three natural soil sites (see Fig. 4) is different from each other. The gravel coarse sand (site-1) with a $\beta$ value of 1.483 has the typical characteristics of pore-size distribution and capillary number and is more suitable for both the movement of water and air, comparing that the very fine sandy loam (site-2) with a $\beta$ value of 0.811 and the sand loamy sand (site-3) with a $\beta$ value of 0.483 are less suitable for water and air movement (see Table 3 ).

The interpretation of parameters $\alpha$ and $\beta$ in Eq. (3) associated with air diffusion into the ground might be highly problematic. It is necessary to perform a confirmatory experiment to verify the results from the natural soil tests. This considers physical interpretation of the mathematical theory of air diffusion by pressure to be easier fitting the parameters in modelling efforts. For example, Millington's relation works well to predict the effective diffusion coefficients in homogeneous soils with relatively
HESSD

A new technique using the

aero-infiltrometer

M. A. Fulazzaky et al.

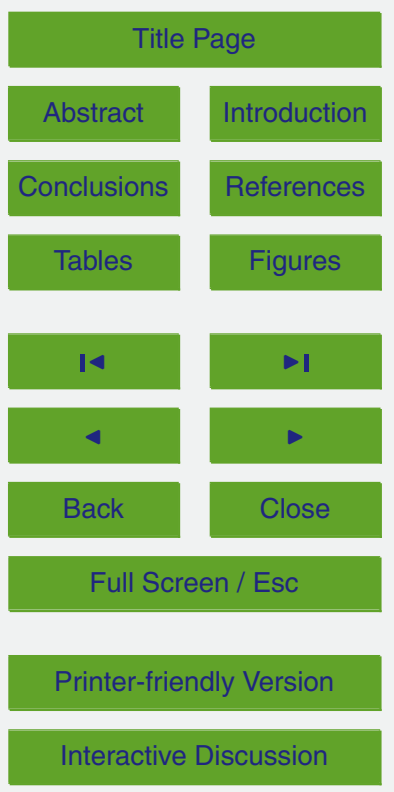


uniform particle-size distributions (Bartelt-Hunt and Smith, 2002). Based on the laboratory test data of using the artificial sandy clay this study found that $\alpha$ value can significantly increase with increasing of the initial- $\theta$, as shown in Table 4 . Under moist air diffusion rate decreases because of the water in vadose zone probably 5 deforms soil, compressing it, or causing cracks (Bouwer, 1986). Its water content makes the soils change dimensions at impregnation and surface roughness degraded to impede air movement. The following suggestions may help identify the properties of the soil, such that: (1) physical interpretation of parameter $\alpha$ relates to permeability of the soil to diffuse air. Supposing that permeability of soil decreases as the initial- $\theta$ 10 increases and thus an increase in $\alpha$ value can be verified based on the laboratory tests. The results confirm that the increase in $\alpha$ value from 0.83 to 0.97 to 1.14 and to $2.68 \mathrm{~cm} \mathrm{kPa}^{-1}$ is due to the initial- $\theta$ increases from 5 to 10 to 15 and to $25 \%$, respectively, and (2) physical interpretation of parameter $\beta$ relates to pore-size distribution and capillary number of the soil. Potential of air diffusion into subsurface can decrease with increasing of the initial- $\theta$ of the soil and thus parameter $\beta$ can be used as indicator of air movement. The results confirm that the decrease in $\beta$ value from 0.639 to 0.584 to 0.581 and to 0.396 is due to the initial- $\theta$ increases from 5 to 10 to 15 and to $25 \%$, respectively (see Table 4). The core of predictive analytics of parameters $\alpha$ and $\beta$ relying on the relationship between $f$ and $P$ is reliable for characterising types of natural soil; therefore, the use of aero-infiltrometer can be useful for the measurements of $f$ and $\theta$ and can be performed anywhere for similar characteristics of the natural soil.

Dry condition of soil can provide high capillary potential and is quite suitable for air and water movement. The fact is that $P$ decreases as the initial- $\theta$ increases. Pore-size distribution and capillary number of soil could effect on air diffusion into the ground. Porosity and pore-size distribution of the soil governs its permeation and can be described in terms of $\beta$ value. Soil particles when adsorb water reduce its capillary potential to diffuse air. Dry soil is a condition for better pore-size distribution and initial capillary number and has a greater hydraulic gradient provided by high capillary potential. Water seeping into capillaries of the soil can change soil texture
HESSD

A new technique using the aero-infiltrometer

M. A. Fulazzaky et al.

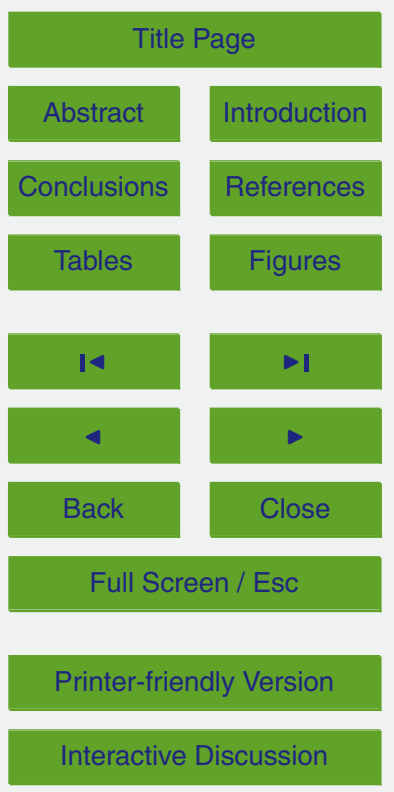


conditionally and makes impediment of air movement. As a consequence, air diffusion into the ground decreases with increasing of the water content. The application of Eq. (3) for measuring $f$ depends on the verification of parameters $\alpha$ and $\beta$ of the soils. Therefore, the future research opportunities need to be addressed as priority the study

\subsection{Moisture characteristics, air diffusion, and soil moisture content}

The interpretation of parameter $\varepsilon$ in Eq. (5) associated with continuous-time of air diffusion into the ground per unit of air pressure might be dependent on permeability of the soil to diffuse air. Capillary potential and relative conductivity in soil can be identified in terms of $\gamma$ value. Parameters $\varepsilon$ and $\gamma$ in Eq. (5) can be useful for determining the moisture characteristics of soil due to soil moisture trends of the natural soils can be differentiated from one another by either the parameters $\varepsilon$ or $\gamma$. The results (Fig. 8) show that application of the different $P$ ranges can differentiate $t$ to saturate air into the ground, depending on nature and properties of the soils. The fluidity and other dynamic 15 physical properties of soil depend on air-water-soil interface. The figure shows that $t$ required to saturate air into the medium-textured soil of very fine sandy loam (site-2) is faster than that into the coarse-textured soil of sand loamy sand (site-3) and then than that into the coarse-textured soil of gravel coarse sand (site-1). Intrinsic permeability of soil makes different continuous-time to diffuse air from the land surface to subsurface.

20 The soil typified by medium-textured soil of very fine sandy loam (site-2) with a $\varepsilon$ value of $5 \times 10^{10} \% \mathrm{~h}^{-1} \mathrm{kPa}^{-1}$ is faster than that by coarse-textured soil of sand loamy sand (site-3) with a $\varepsilon$ value of $6 \times 10^{4} \% \mathrm{~h}^{-1} \mathrm{kPa}^{-1}$ and then than that by gravel coarse sand (site-1) with a $\varepsilon$ value of $2 \times 10^{3} \% \mathrm{~h}^{-1} \mathrm{kPa}^{-1}$ to diffuse air from the surface to subsurface land (see Table 3). The presence of organic matter in the coarse-textured soil of gravel soil particles together to impede air movement. The aggregation is quite difficult for the coarse-textured soil of sand loamy sand with an initial- $\theta$ of $3.5 \%$ (site-3) and for the medium-textured soil of very fine sandy loam with an initial- $\theta$ of $1.0 \%$ (site-2),

A new technique using the aero-infiltrometer

M. A. Fulazzaky et al.

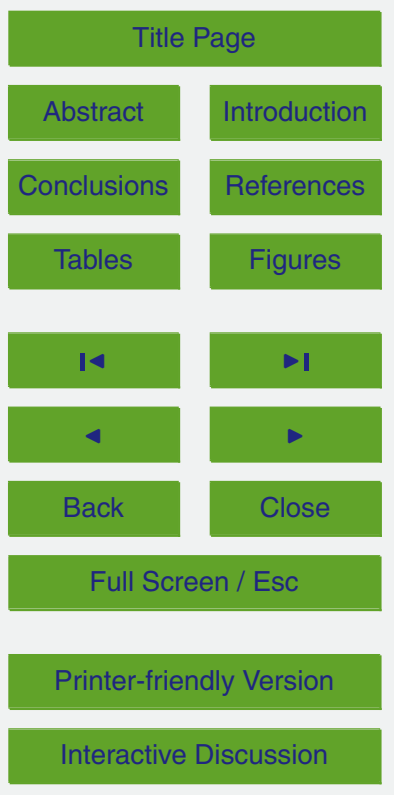


because they have a low initial- $\theta$. With drier soil conditions in dry season, air diffusion into the ground is rapid enough for permeability of the soil, indicating that $\varepsilon$ value is quite important. Continuous-time is short for dry soil because of its permeability to saturate air is high. The $\theta$ model (Fig. 8) shows that the continuous-time of 10 min for 5 the medium-textured soil of very fine sandy loam (site-2) is significantly faster than that of $24 \mathrm{~min}$ for the coarse-textured soil of sand loamy sand (site-3) and then than that of 25 min for the coarse-textured soil of gravel coarse sand (site-1).

A theoretic approach for interpretation of air diffusion into the ground considers that water contained in vadose zone has a negative pressure head which is below than 10 the atmospheric pressure (Kresic, 2007). The negative $\gamma$ value (see Tables 3 and 4) might be related to negative air pressure in soil and would record as a suggestion. Air with an initial pressure of $117 \mathrm{kPa}$ can move from the air tank to the medium-textured soil of very fine sandy loam (site-2) with a $\gamma$ value of -3.25 faster than that to the coarse-textured soil of sand loamy sand (site-3) with a $\gamma$ value of -1.60 and then than that to the coarse-textured soil of gravel coarse sand (site-1) with a $\gamma$ value of -0.73 (see Table 3). A typical $\gamma$ value of the soil is dependent on porosity which relies on its capillary potential and relative conductivity. As a consequence, the continuous-time to saturate air from the surface to subsurface land is dependent on the texture and structure of the soil.

20 In the previous studies by DiGiulio (1992) and Suthersan (1999) have reported that air permeability in soil is a function of the soil's intrinsic permeability and liquid content. In this study, a research question can be made into a hypothesis that air permeability in a soil is good for drier soil conditions of low $\theta$. The change in $\varepsilon$ value related to initial$\theta$ was analysed accounting for dynamic properties of soil-air interface and requires 25 a quantitative understanding of the process in a vadose-zone. The results (Table 4) of testing the artificial sandy clay validate this hypothesis and show the decrease in $\varepsilon$ value from $9 \times 10^{7}$ to $4 \times 10^{5}$ to $3 \times 10^{5}$ and to $6 \times 10^{4} \% \mathrm{~h}^{-1} \mathrm{kPa}^{-1}$ with increasing of the initial- $\theta$ from 5 to 10 to 20 and to $25 \%$, respectively. It is suggested that air diffusion into a dry vadose zone is favourable because of the soil pore space is sufficiently important.
HESSD

$11,2515-2553,2014$

A new technique

using the

aero-infiltrometer

M. A. Fulazzaky et al.

Title Page

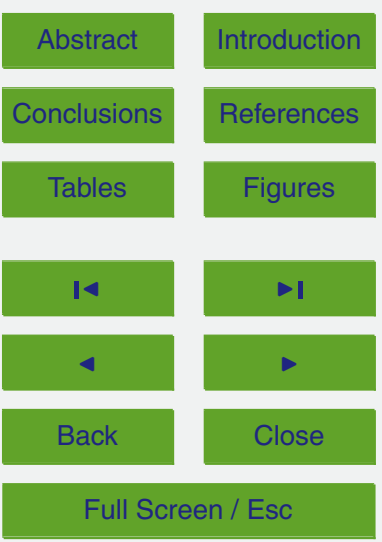

Printer-friendly Version

Interactive Discussion 
Air can diffuse rapidly from the land surface to subsurface because of the passage of air particles through the large soil pores distribution has a high concentration gradient (Fulazzaky, 2011; Fulazzaky et al., 2013). Air permeability in the soil decreases with $\theta$ there is due to water can seep into the soil to reduce void spaces. The ability of a soil 5 to freely transmit air is favourable for drier soil conditions due to capillary potential and relative conductivity is sufficiently conducive when air pressure in a vadose zone is below than the atmospheric pressure. The results (Table 4) obtained from the laboratory tests for the assessment of artificial sandy clay show that capillary potential and relative conductivity of the soil increase with increasing of the initial- $\theta$ judging the 10 increase in $\gamma$ value from -2.89 to -1.69 to -1.64 and to -1.36 with increasing of the initial- $\theta$ from 5 to 10 to 20 and to $25 \%$, respectively. Air permeability in a soil is dependent on air pressure head, pore size distribution, and capillary number. Initial differences in structure and porosity as reported by Foley et al. (2006) were transient and related to $\theta$. It has been found (see Table 4) that the decrease in $\varepsilon$ value and the increase in $\gamma$ value with increasing of the initial- $\theta$ seem to be a better indicator for describing air permeability in soils. The continuous-time to air and water flow into the ground must be readily accessible to actual condition, theoretically starting from any initial- $\theta$ up to soil's saturation $(\theta=100 \%)$ and is dependent on capillary potential and relative conductivity of the soil.

\section{Conclusions}

This study used the data of $L_{\mathrm{p}}$ reading from the aero-infiltrometer and $L_{\mathrm{w}}$ reading from the double-ring infiltrometer to establish the empirical models. The models must be calibrated and validated before they can be used for the measurements of $f$ and $\theta$ of the soils. The empirical models were verified using independent datasets from three natural soil sites. Functional infiltration expressions accounting for air pressure and soil porosity in relation with depth of air movement into the ground and characteristics of the soil were presented. Functional soil moisture expressions accounting for air
HESSD

11, 2515-2553, 2014

A new technique

using the

aero-infiltrometer

M. A. Fulazzaky et al.

Title Page

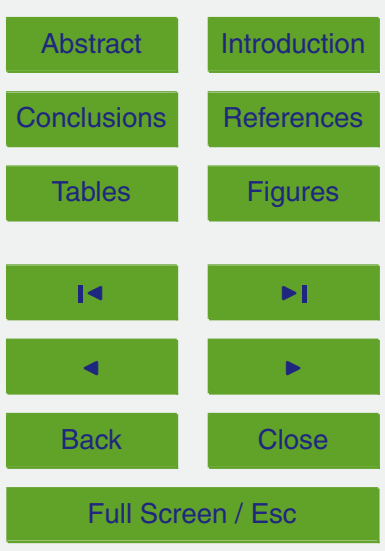

Printer-friendly Version

Interactive Discussion 
pressure and soil porosity in relation with continuous-time, capillary potential, and relative conductivity were presented as well. All the parameters in equations have physical interpretation, and experimental data validation showed that the equations are sufficiently accurate. Aero-infiltrometer using air as dynamic vector has been 5 proposed as a new device for the measurements of $f$ and $\theta$ and gives a forum in understanding the dynamic and hydraulic properties of the soil in a vadose zone. The use of aero-infiltrometer to determine $f$ and $\theta$ is helpful due to easy and modest equipment is suitable to be used at any places of critical land. Once the aeroinfiltrometer has been calibrated for any specific characteristics of the soils, the use 10 of such device can be useful to determine $f$ and $\theta$ at anywhere of either a flat or a slanted land. The advantages of aero-infiltrometer are that: (1) the use of air as dynamic vector is available anywhere, (2) the time period for data collection is significantly faster comparing that using the traditional infiltrometers, (3) the physical interpretation of circumstances of air-confining vadose zone may be simplified in terms of the parameters in equations, and (4) the use of only two parameters i.e., $\alpha$ and $\beta$ for measuring $f$ as well as $\varepsilon$ and $\gamma$ for measuring $\theta$ is simple in calculation and can minimise the possibility of misinterpretation of the data.

Acknowledgements. This study used the financial supports of Short Grant (SG) Vot. No 0562 from Universiti Tun Hussein Onn Malaysia and Academic Visitor Grant (AVG) Vot. No 4D058

20 from Universiti Teknologi Malaysia. The SG and AVG provided by the universities are greatly appreciated.

\section{References}

Abdulkadir, A., Abdu, N., and Jibril, I.: Application of Kozeny-Carman equation to estimate saturated hydraulic conductivity of an alfisol at Samaru and a cambisol at Kadawa, Nigeria, Nigerian Journal of Basic and Applied Sciences, 20, 116-124, 2012.

Aharmouch, A. and Amaziane, B.: Development and evaluation of a numerical model for steady state interface and/or free surface groundwater flow, J. Hydrol., 434-435, 110-120, doi:10.1016/j.jhydrol.2012.02.027, 2012.
HESSD

11, 2515-2553, 2014

A new technique

using the

aero-infiltrometer

M. A. Fulazzaky et al.

Title Page

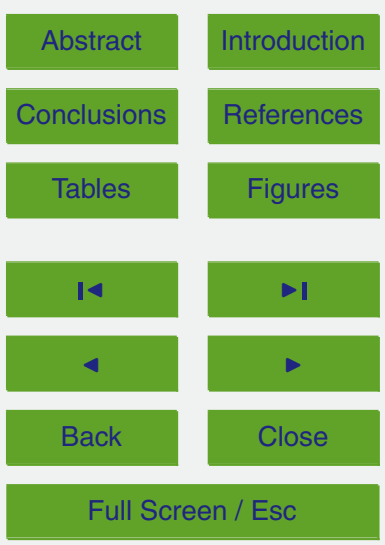

Printer-friendly Version

Interactive Discussion 
Akan, A. O.: Urban Stromwater Hydrology: A Guide to Engineering Calculations, Technomic Publishing Co. Inc., Lancaster, 1993.

Allaire, S. E., Lafond, J. A., Cabral, A. R., and Lange, S. F.: Measurement of gas diffusion through soils: comparison of laboratory methods, J. Environ. Monitor., 10, 1326-1336, 5 doi:10.1039/b809461f, 2008.

Althaus, R., Klump, S., Onnis, A., Kipfer, R., Purtschert, R., Stauffer, F., and Kinzelbach, W.: Noble gas tracers for characterisation of flow dynamics and origin of groundwater: a case study in Switzerland, J. Hydrol., 370, 64-72, doi:10.1016/j.jhydrol.2009.02.053, 2009.

Bartelt-Hunt, S. L. and Smith, J. A.: Measurement of effective air diffusion coefficients for trichloroethene in undisturbed soil cores, J. Contam. Hydrol., 56, 193-208, doi:10.1016/S0169-7722(01)00209-1, 2002.

Bedient, P. B. and Huber, W. C.: Hydrology and Floodplain Analysis, Addison Wesley Publishing Co., New York, 1992.

Bouwer, H.: Intake rate: cylindrical infiltrometer, in: Methods of Soil Analysis, 2nd Edn., edited by: Klute, A., Soil Science Society of America, Madison, Wisconsin, 825-843, 1986.

Brady, N. C. and Weil, R. R.: The Nature and Properties of Soils, 13th Edn., Prentice-Hall Inc., Upper Saddle River, New Jersey, 2002.

Davidson, E. A. and Trumbore, S. E.: Gas diffusivity and production of $\mathrm{CO}_{2}$ in deep soils of the eastern Amazon, Tellus B, 47, 550-565, doi:10.1034/j.1600-0889.47.issue5.3.x, 1995.

Davis, L. D. and Masten, S. J.: Principles of Environmental Engineering and Science, Mc Graw Hill, Boston, 2004.

Diamond, J. and Shanley, T.: Infiltration rate assessment of some major soils, Irish Geography, 36, 32-46, 2003.

Dingman, S. L.: Water in soils - infiltration and redistribution, in: Physical Hydrology, 2nd Edn., Prentice-Hall, Inc. Upper Saddle River, New Jersey, Chapter 6, 2002.

Foley, J. L., Tolmie, P. E., and Silburn, D. M.: Improved measurement of conductivity on swelling clay soils using a modified disc permeameter method, Aust. J. Soil Res., 44, 701-710, doi:10.1071/SR05195, 2006.

Fredlund, D. G., Rahardjo, H., and Fredlund, M. D.: Unsaturated Soil Mechanics in Engineering Practice, John Wiley \& Sons, Hoboken, NJ, 2012.

Fulazzaky, M. A.: Determining the resistance of mass transfer for adsorption of the surfactant onto granular activated carbons from hydrodynamic column, Chem. Eng. J., 166, 832-840, doi:10.1016/j.cej.2010.11.052, 2011.

A new technique

using the

aero-infiltrometer

M. A. Fulazzaky et al.

Title Page

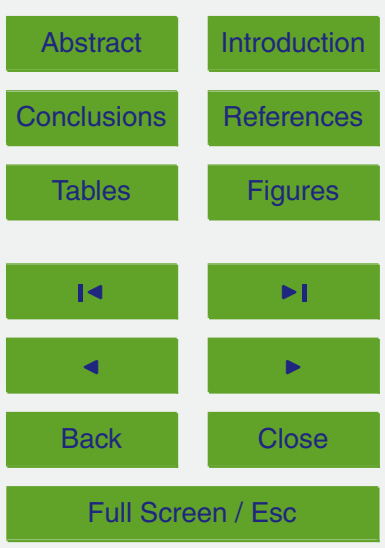

Printer-friendly Version

Interactive Discussion 
Fulazzaky, M. A. and Gany, A. H. A.: Challenges of soil erosion and sludge management for sustainable development in Indonesia, J. Environ. Manage., 90, 2387-2392, doi:10.1016/j.jenvman.2009.02.017, 2009.

Fulazzaky, M. A., Kassim, A. H. M., and Ibrahim, I.: Measuring the infiltration rate and soil moisture content by using aero-infiltration tool in order to optimize agricultural water uses, in: The 20th Congress on Irrigation and Drainage, Lahore, Pakistan, 13-18 October 2008, 189-204, 2008.

Fulazzaky, M. A., Ismail, I., and Kassim, A. H. M.: Feasibility to use aero-infiltrometer in measuring of the infiltration rate and soil moisture content, in: International Conference on

10 Water Resources, Langkawi, Malaysia, 26-27 May 2009, 2009a.

Fulazzaky, M. A., Ismail, I., and Kassim, A. H. M.: Empirical models of aero-infiltromater to measure the infiltration rate and soil moisture content, in: The 3rd Regional Conference on Natural Resources in the Tropics, Kuching, Malaysia, 2-5 August 2009, 2009b.

Fulazzaky, M. A., Khamidun, M. H., and Omar, R.: Understanding of mass transfer resistance 15 for the adsorption of solute onto porous material from the modified mass transfer factor models, Chem. Eng. J., 228, 1023-1029, doi:10.1016/j.cej.2013.05.100, 2013.

Han, X. W., Shao, M. A., and Horton, R.: Estimating van Genuchten model parameters of undisturbed soils using an integral method, Pedosphere, 20, 55-62, doi:10.1016/S10020160(09)60282-4, 2010.

20 Hartmann, A., Weiler, M., Wagener, T., Lange, J., Kralik, M., Humer, F., Mizyed, N., Rimmer, A., Barberá, J. A., Andreo, B., Butscher, C., and Huggenberger, P.: Process-based karst modelling to relate hydrodynamic and hydrochemical characteristics to system properties, Hydrol. Earth Syst. Sci., 17, 3305-3321, doi:10.5194/hess-17-3305-2013, 2013.

Hillel, D.: Fundamentals of Soil Physics, Academic Press, New York, 1980.

Horton, R. E.: An approach toward a physical interpretation of infiltration capacity, Eos. T. Am. Geophys. Un., 20, 692-711, 1939.

Ippisch, O., Vogel, H. J., and Bastian, P.: Validity limits for the van Genuchten-Mualem model and implications for parameter estimation and numerical simulation, Adv. Water Resour., 29, 1780-1789, doi:10.1016/j.advwatres.2005.12.011, 2006.

30 Jarvis, N., Koestel, J., Messing, I., Moeys, J., and Lindahl, A.: Influence of soil, land use and climatic factors on the hydraulic conductivity of soil, Hydrol. Earth Syst. Sci., 17, 5185-5195, doi:10.5194/hess-17-5185-2013, 2013.

A new technique using the

aero-infiltrometer

M. A. Fulazzaky et al.

Title Page

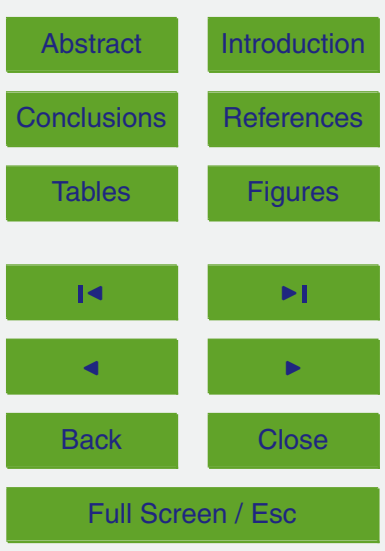

Printer-friendly Version

Interactive Discussion 
Kopec, D. M.: Soil Characteristics and How They Affect Soil Moisture, Turf Tips-Cooperative Extension, Volume II, Issue 10, Arizona Board of Regents, Arizona, 1995.

Kostiakov, A. N.: On the Dynamic of the Coefficient of Water Percolation in Soils and on the Necessity of Studying it from a Dynamic Point of View for the Purposes of Amelioration, Russia, 1932.

Kresic, N.: Hydrogeology and Groundwater Modeling, 2nd Edn., CRC Press, New York, 2007.

Kumar, P.: Layer averaged Richard's equation with lateral flow, Adv. Water Resour., 27, 521531, doi:10.1016/j.advwatres.2004.02.007, 2004.

Kutlu, T. and Ersahin, S.: Calibration of van Genuchten unsaturated hydraulic conductivity parameters by regression technique, in: International Meeting on Soil Fertility, Land Management and Agroclimatology, Kusadasi, Turkey, 29 October-1 November 2008, 175181, 2008.

Kyrke-Smith, T. M., Katz, R. F., and Fowler, A. C.: Subglacial hydrology and the formation of ice 15

streams, P. Roy. Soc. A-Math. Phy., 470, 20130494, doi:10.1098/rspa.2013.0494, 2014.

Lassabatère, L., Angulo-Jaramillo, R., Soria Ugalde, J. M., Cuenca, R., Braud, I., and Haverkamp, R.: Beerkan estimation of soil transfer parameters through infiltration experiments-BEST, Soil Sci. Soc. Am. J., 70, 521-532, doi:10.2136/sssaj2005.0026, 2006.

Lawrence, J. E. and Hornberger, G. M.: Soil moisture variability across climate zones, Geophys. Res. Lett., 34, L20402, doi:10.1029/2007GL031382, 2007.

Liu, J.-G. and Xie, Z.-H.: Improving simulation of soil moisture in China using a multiple meteorological forcing ensemble approach, Hydrol. Earth Syst. Sci., 17, 3355-3369, doi:10.5194/hess-17-3355-2013, 2013.

Liu, X., Yo, X., and Xu, S.: A new method to estimate the parameters of van Genuchten retention model using degree of phosphorus saturation (DPS), Afr. J. Agric. Res., 6, 4800-4806, doi:10.5897/AJAR11.700, 2011.

$\mathrm{Ma}$, J., Wang, Z.-Y., Stevenson, B. A., Zheng, X.-J., and Li, Y.: An inorganic $\mathrm{CO}_{2}$ diffusion and dissolution process explains negative $\mathrm{CO}_{2}$ fluxes in saline/alkaline soils, Scientific Reports, 3, 2025, doi:10.1038/srep02025, 2013.

30 Madsen, M. D. and Chandler, D. G.: Automation and use of mini disk infiltrometers, Soil Sci. Soc. Am. J., 71, 1469-1472, doi:10.2136/sssaj2007.0009N, 2007.

\section{HESSD}

$11,2515-2553,2014$

A new technique

using the

aero-infiltrometer

M. A. Fulazzaky et al.

Title Page

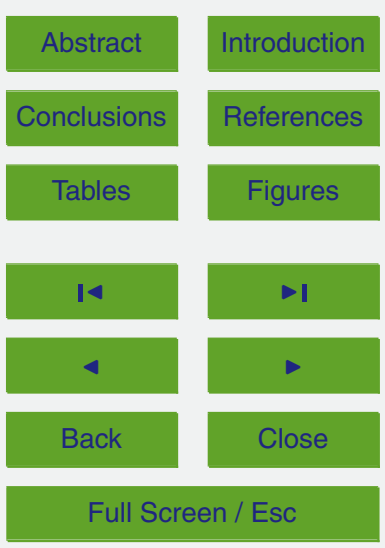

Printer-friendly Version

Interactive Discussion 
Mirus, B. B. and Perkins, K. S.: Practical estimates of field-saturated hydraulic conductivity of bedrock outcrops using a modified bottomless bucket method, Water Resour. Res., 48, 9, doi:10.1029/2012WR012053, 2012.

Nimmo, J. R., Schmidt, K. M., Perkins, K. S., and Stock, J. D.: Rapid measurement of field5 saturated hydraulic conductivity for areal characterization, Vadose Zone J., 8, 142-149, doi:10.2136/vzj2007.0159, 2009.

Novák, V., Kňava, K., and Šimůnek, J.: Determining the influence of stones on hydraulic conductivity of saturated soils using numerical method, Geoderma, 161, 177-181, doi:10.1016/j.geoderma.2010.12.016, 2011.

10 Petersen, L. W., Rolston, D. E., Moldrup, P., and Yamaguchi, T.: Volatile organic vapor diffusion and adsorption in soils, J. Environ. Qual., 23, 799-805, 1994.

Peyraube, N., Lastennet, R., and Denis, A.: Geochemical evolution of groundwater in the unsaturated zone of a karstic massif, using the $\mathrm{P}_{\mathrm{CO}_{2}}$-Slc relationship, J. Hydrol., 430-431, 13-24, doi:10.1016/j.jhydrol.2012.01.033, 2012.

Ravi, V. and Williams, J. R.: Estimation of Infiltration Rate in the Vadose Zone: Compilation of Simple Mathematical Models, Vol. I, EPA/600/R-97-128a, USEPA, Oklahoma, 1998.

Reynolds, W. D., Elrick, D. E., and Youngs, E. G.: Ring or cylinder infi Itrometers (vadose zone), in: Methods of Soil Analysis, Part 4: Physical Methods, edited by: Dane, J. H. and Topp, G. C., SSSA, Madison, WI, 818-843, 2002.

20 Valiantzas, J. D.: Combined Brooks-Corey/Burdine and van Genuchten/Mualem closed-form model for improving prediction of unsaturated conductivity, J. Irrig. Drain. E.-ASCE, 137, 223-233, doi:10.1061/(ASCE)IR.1943-4774.0000284, 2011.

van Genuchten, M. T.: A closed-form equation for predicting the hydraulic conductivity of unsaturated soils, Soil Sci. Soc. Am. J., 44, 892-898, 1980.

Wang, G., Jiang, H., Xu, Z., Wang, L., and Yue, W.: Evaluating the effect of land use changes on soil erosion and sediment yield using a grid-based distributed modelling approach, Hydrol. Process., 26, 3579-3592, doi:10.1002/hyp.9193, 2012.

Wang, Z., Feyen, J., Nielsen, D. R., and van Genuchten, M. T.: Two-phase flow infiltration equations accounting for air entrapment effects, Water Resour. Res., 33, 2759-2767, doi:10.1029/97WR01708, 1997.

Wanielista, M.: Hydrology and Water Quantity Control, John Wiley \& Sons, Inc., New York, 1990.

A new technique using the

aero-infiltrometer

M. A. Fulazzaky et al.

Title Page

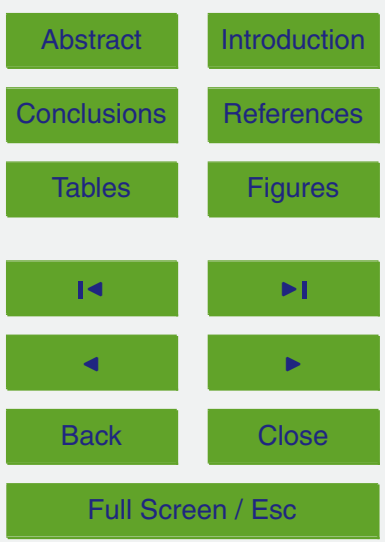

Printer-friendly Version

Interactive Discussion 
Wanielista, M., Kersten, R., and Eaglin, R.: Hydrology - Water Quantity and Water Quality Control, 2nd Edn., John Wiley \& Sons, Inc., New York, 1997.

Xu, Q., Liu, S., Wan, X., Jiang, C., Song, X., and Wang, J.: Effects of rainfall on soil moisture and water movement in a subalpine dark coniferous forest in southwestern China, Hydrol.

Process., 26, 3800-3809, doi:10.1002/hyp.8400, 2012.

HESSD

$11,2515-2553,2014$

A new technique

using the

aero-infiltrometer

M. A. Fulazzaky et al.

Title Page

Abstract

Introduction

Conclusions

References

Tables

Figures

14

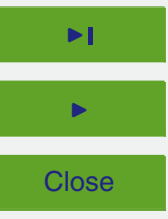

Back

Close

Full Screen / Esc

Printer-friendly Version

Interactive Discussion 
Table 1. An example of the results of aero-infiltrometer and double-ring infiltrometer test collected from site-1.

\begin{tabular}{|c|c|c|c|c|c|c|c|c|c|c|c|}
\hline \multicolumn{2}{|c|}{ Al } & \multicolumn{2}{|c|}{ DRI } & \multirow{2}{*}{$\begin{array}{l}\text { Cum.t } \\
\text { (mn) }\end{array}$} & \multirow{2}{*}{$\begin{array}{r}\text { Cum. } L_{p} \\
(\mathrm{kPa})\end{array}$} & \multirow{2}{*}{$\begin{array}{c}\text { Cum. } L_{\mathrm{w}} \\
\text { (cm) }\end{array}$} & $P$ & $f_{\text {exp }}$ & $f_{\text {th }}$ & $\theta_{\exp }$ & \multirow[t]{2}{*}{$\theta_{\text {th }}$} \\
\hline $\begin{array}{l}t_{\mathrm{av}} \\
(\mathrm{s}) \\
(1)\end{array}$ & $\begin{array}{c}L_{p} \\
(p s i) \\
(2)\end{array}$ & $\begin{array}{l}t \\
(s) \\
(3)\end{array}$ & $\begin{array}{c}L_{\mathrm{w}} \\
(\mathrm{cm}) \\
(4)\end{array}$ & & & & $\begin{array}{r}\left(\mathrm{kPah}^{-1}\right) \\
(8)\end{array}$ & $\begin{array}{r}\left(\mathrm{cmh}^{-1}\right) \\
(9)\end{array}$ & $\begin{array}{r}\left(\mathrm{cm} \mathrm{h}^{-1}\right) \\
(10)\end{array}$ & $\begin{array}{l}(\%) \\
(11)\end{array}$ & \\
\hline 0 & 17.0 & 0 & 5.0 & 0.0 & 0.0 & 0.0 & 443 & 80.6 & 76.9 & 21.8 & 24.7 \\
\hline 40 & 16.5 & & & 0.7 & 3.4 & 0.5 & 310 & 47.1 & 45.5 & 30.8 & 31.7 \\
\hline 121 & 16.0 & & & 2.0 & 6.9 & 0.8 & 205 & 22.3 & 24.7 & 44.1 & 42.2 \\
\hline 294 & 15.5 & & & 4.9 & 10.3 & 1.0 & 127 & 12.3 & 12.2 & 58.9 & 59.0 \\
\hline & & 300 & 4.0 & 5.0 & 10.5 & 1.0 & 125 & 12.0 & 12.0 & 58.8 & 59.3 \\
\hline 532 & 15.0 & & & 8.9 & 13.8 & 1.2 & 93 & 8.2 & 7.8 & 71.5 & 72.9 \\
\hline & & 600 & 3.7 & 10.0 & 15.1 & 1.3 & 91 & 7.8 & 7.5 & 76.5 & 74.3 \\
\hline & & 900 & 3.6 & 15.0 & 18.8 & 1.4 & 75 & 5.6 & 5.6 & 82.4 & 84.7 \\
\hline & & 1200 & 3.4 & 20.0 & 21.9 & 1.6 & 66 & 4.8 & 4.6 & 94.1 & 93.0 \\
\hline & & 1500 & 3.3 & 25.0 & 24.6 & 1.7 & 59 & 4.1 & 4.0 & 100.0 & 100.0 \\
\hline & & 1800 & 3.3 & 30.0 & 27.1 & 1.7 & 54 & 3.4 & 3.5 & 100.0 & \\
\hline & & 2100 & 3.3 & 35.0 & 29.4 & 1.7 & 50 & 2.9 & 3.1 & 100.0 & \\
\hline
\end{tabular}

Notes: Al is Aero-infiltrometer, DRI is double-ring infiltrometer, Cum. $L_{p}$ is cumulative level of the air pressure drop (in $\mathrm{kPa}$ ), Cum. $L_{\mathrm{w}}$ is cumulative decreasing of the water level (in cm), Cum. $t$ is cumulative test time (in $\mathrm{mn}$ ), $f_{\exp }$ is experimental infiltration rate $\left(\mathrm{cmh}^{-1}\right)$, $f_{\text {th }}$ is theoretical infiltration rate $\left(\mathrm{cmh}^{-1}\right), L_{\mathrm{p}}$ is level of the air pressure drop (in $\mathrm{kPa}$ ), $L_{\mathrm{w}}$ is decreasing of the water level (in $\mathrm{cm}$ ), $P$ is air pressure dropping rate (in $\mathrm{kPah}^{-1}$ ), $t$ is test time (in s), $t_{\mathrm{av}}$ is average test time (in $\mathrm{s}$ ), $\theta_{\mathrm{exp}}$ is experimental soil moisture content (in \%), $\theta_{\mathrm{th}}$ is theoretical soil moisture content (in \%).

\section{A new technique using the aero-infiltrometer \\ M. A. Fulazzaky et al.}

Title Page

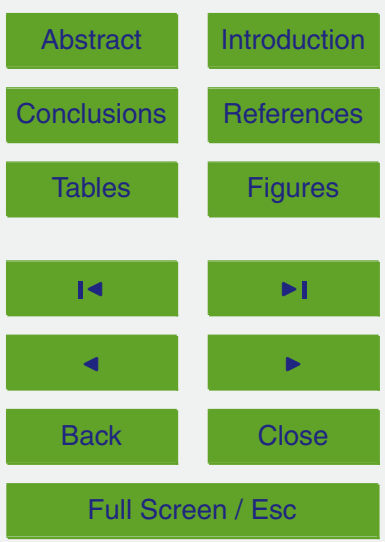

Printer-friendly Version

Interactive Discussion 
Table 2. Analysis of $R^{2}$ from trial of linear, logarithmic, exponential and power regression.

\begin{tabular}{lllll}
\hline Location of measurement & \multicolumn{4}{c}{ Correlation coefficient, $R^{2}$} \\
\cline { 2 - 5 } & linear & logarithmic & exponential & power \\
\hline \multicolumn{2}{l}{ Trial for infiltration rate correlation } \\
Site-1 & 0.9754 & 0.8452 & 0.9246 & 0.9977 \\
Site-2 & 0.8563 & 0.9263 & 0.9252 & 0.9583 \\
Site-3 & 0.8646 & 0.8488 & 0.7058 & 0.9422 \\
Trial for soil moisture content correlation & & \\
Site-1 & 0.8471 & 0.9685 & 0.9507 & 0.9940 \\
Site-2 & 0.7589 & 0.8553 & 0.9608 & 0.9821 \\
Site-3 & 0.6629 & 0.8773 & 0.9362 & 0.9965 \\
\hline
\end{tabular}

Note: $R^{2}$ is correlation coefficient

HESSD

11, 2515-2553, 2014

A new technique

using the

aero-infiltrometer

M. A. Fulazzaky et al.

Title Page

Abstract

Introduction

Conclusions

References

Tables

Figures

14

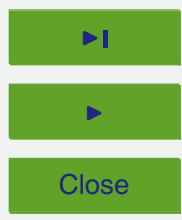

Back

Close

Full Screen / Esc

Printer-friendly Version

Interactive Discussion 


\section{HESSD}

11, 2515-2553, 2014

A new technique

using the

aero-infiltrometer

M. A. Fulazzaky et al.

Table 3. Values of $\alpha, \beta, \varepsilon$ and $\gamma$ for the different sites of natural soil investigation.

\begin{tabular}{llllllll}
\hline \multirow{2}{*}{ Location of investigation } & \multicolumn{3}{c}{ Curve $f_{\mathrm{th}}=\alpha \cdot P^{\beta}$} & & \multicolumn{3}{c}{ Curve $\theta_{\mathrm{th}}=\varepsilon \cdot P^{\gamma}$} \\
\cline { 2 - 5 } \cline { 6 - 8 } & $\alpha\left(\mathrm{cm} \mathrm{kPa}^{-1}\right)$ & $\beta$ & $R^{2}$ & & $\varepsilon\left(\% \mathrm{~h}^{-1} \mathrm{kPa}^{-1}\right)$ & $\gamma$ & $R^{2}$ \\
\hline Site-1 & 0.009 & 1.483 & 0.9977 & & $2 \times 10^{3}$ & -0.73 & 0.9940 \\
Site-2 & 0.014 & 0.811 & 0.9583 & & $5 \times 10^{10}$ & -3.25 & 0.9821 \\
Site-3 & 1.886 & 0.483 & 0.9422 & & $6 \times 10^{4}$ & -1.60 & 0.9965 \\
\hline
\end{tabular}

Notes: $f_{\mathrm{th}}$ is theoretical infiltration rate $\left(\mathrm{cmh}^{-1}\right), P$ is air pressure dropping rate (in $\left.\mathrm{kPah}^{-1}\right), R^{2}$ is correlation coefficient (dimensionless), $\alpha$ is air diffusion coefficient relying the depth of air movement into the ground per unit of pressure (in $\left.\mathrm{cm} \mathrm{kPa}^{-1}\right), \beta$ is diffusion index relying the size and number of capillaries through which air moves from the surface to subsurface land (dimensionless), $\varepsilon$ is soil-air matrix potential coefficient relying the continuous-time to saturate air into the ground per unit of pressure (in $\% \mathrm{~h}^{-1} \mathrm{kPa}^{-1}$ ), and $\gamma$ is air-filled porosity index related to capillary potential and relative conductivity (dimensionless), $\theta_{\text {th }}$ is theoretical soil moisture content (in \%).

\section{Title Page}

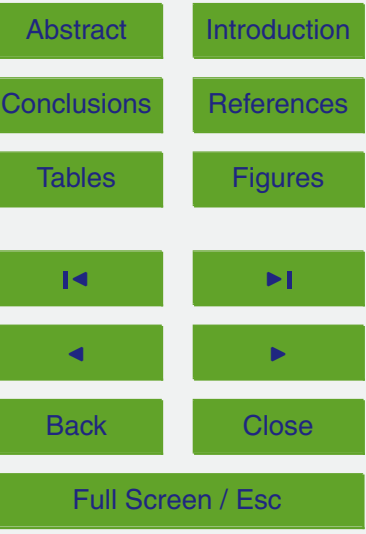

Printer-friendly Version

Interactive Discussion 


\section{HESSD}

$11,2515-2553,2014$

A new technique

using the

Table 4. Values of $\alpha, \beta, \varepsilon$ and $\gamma$ for artificial sandy clay tested with the different initial- $\theta$.

\section{aero-infiltrometer}

M. A. Fulazzaky et al.

\begin{tabular}{llllllll}
\hline Initial- $\theta(\%)$ & \multicolumn{3}{c}{ Curve $_{\text {th }}=\alpha \cdot P^{\beta}$} & & \multicolumn{3}{c}{ Curve $\theta_{\text {th }}=\varepsilon \cdot P^{\gamma}$} \\
\cline { 2 - 5 } \cline { 7 - 8 } & $\alpha\left(\mathrm{cmkPa}^{-1}\right)$ & $\beta$ & $R^{2}$ & & $\varepsilon\left(\% \mathrm{~h}^{-1} \mathrm{kPa}^{-1}\right)$ & $\gamma$ & $R^{2}$ \\
\hline 5 & 0.83 & 0.639 & 0.9384 & & $9 \times 10^{7}$ & -2.89 & 0.9293 \\
10 & 0.97 & 0.584 & 0.9992 & & $4 \times 10^{5}$ & -1.69 & 0.9874 \\
15 & 1.14 & 0.581 & 0.9939 & & - & - & - \\
20 & - & - & - & & $3 \times 10^{5}$ & -1.64 & 0.9814 \\
25 & 2.68 & 0.396 & 0.9767 & & $6 \times 10^{4}$ & -1.36 & 0.9895 \\
\hline
\end{tabular}

Notes: $f_{\text {th }}$ is theoretical infiltration rate $\left(\mathrm{cm} \mathrm{h}^{-1}\right), P$ is air pressure dropping rate (in $\left.\mathrm{kPah}^{-1}\right), R^{2}$ is correlation coefficient (dimensionless), $\alpha$ is air diffusion coefficient relying the depth of air movement into the ground per unit of pressure (in $\mathrm{cm} \mathrm{kPa}^{-1}$ ), $\beta$ is diffusion index relying the size and number of capillaries through which air moves from the surface to subsurface land (dimensionless), $\varepsilon$ is soil-air matrix potential coefficient relying the continuous-time to saturate air into the ground per unit of pressure (in $\% \mathrm{~h}^{-1} \mathrm{kPa}^{-1}$ ), and $\gamma$ is air-filled porosity index related to capillary potential and relative conductivity (dimensionless), $\theta_{\text {th }}$ is theoretical soil moisture content (in \%).

Title Page

Abstract

Introduction

Conclusions

References

Tables

Figures

14

4

Back

Close

Full Screen / Esc

Printer-friendly Version

Interactive Discussion 


\section{HESSD}

$11,2515-2553,2014$

A new technique using the

aero-infiltrometer

M. A. Fulazzaky et al.

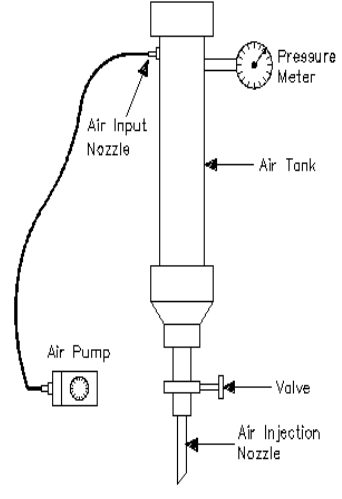

(a)

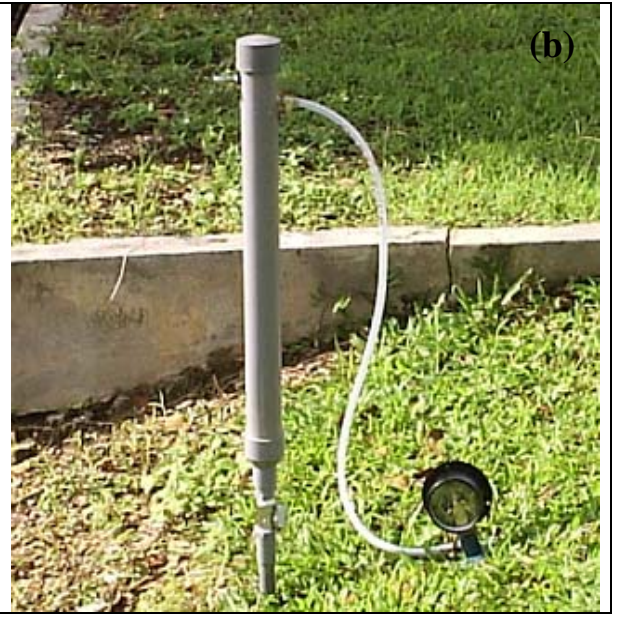

Fig. 1. Image of the aero-infiltrometer for (a) schematic and (b) physical model.

Title Page

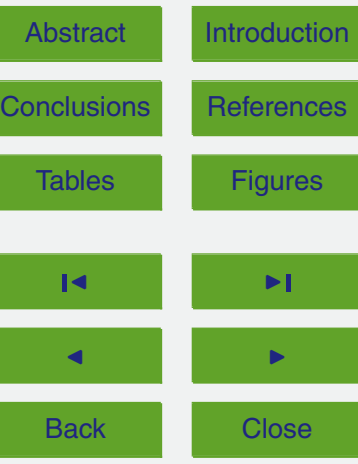

Full Screen / Esc

Printer-friendly Version

Interactive Discussion

(c) (1) 


\section{HESSD}

11, 2515-2553, 2014

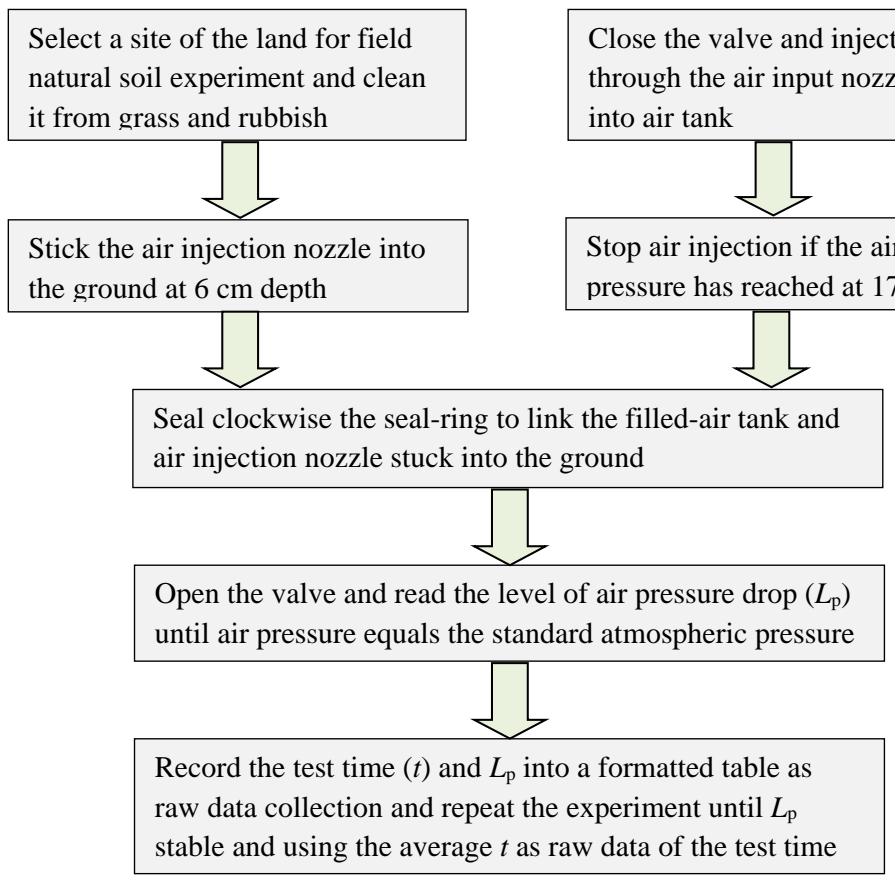

\section{A new technique using the aero-infiltrometer \\ M. A. Fulazzaky et al.}

Title Page

Abstract Introduction

Conclusions

References

Tables

Figures

14

1

4

Back

Close

Full Screen / Esc

Printer-friendly Version

Interactive Discussion 
(a)
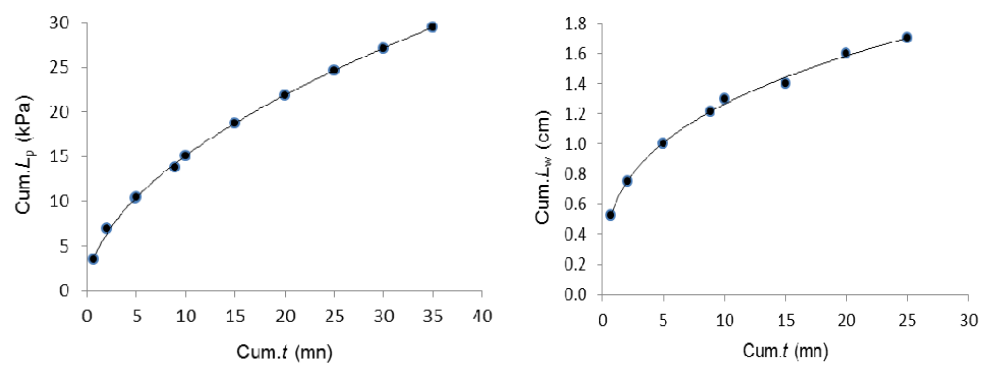

(c)
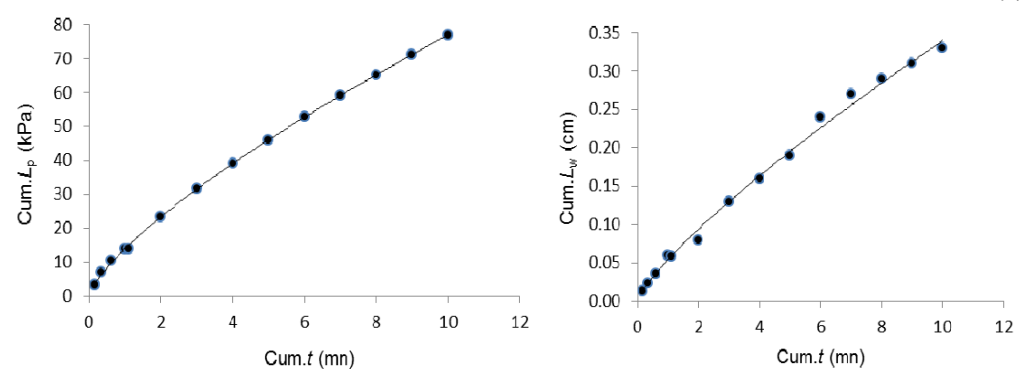

(e)
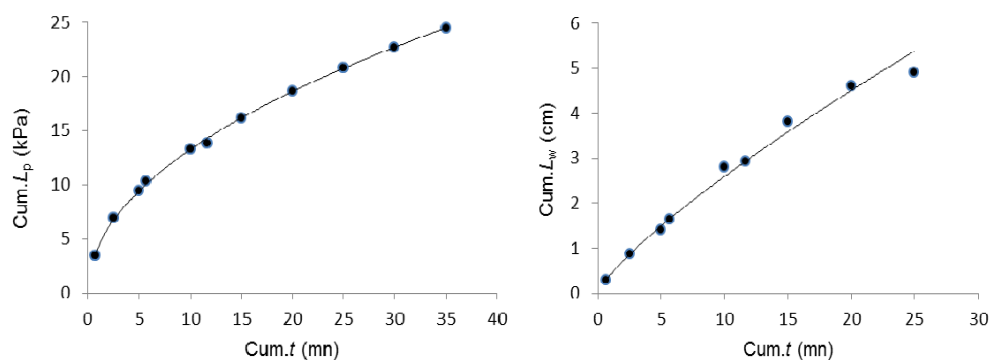

Fig. 3. Calibration of Cum. $L_{p}$ using the curves of Cum. $L_{p}$ vs. Cum.t; with (a) site-1, (c) site-2, and (e) site-3 and calibration of Cum. $L_{\mathrm{w}}$ using the curves of Cum. $L_{\mathrm{w}}$ vs. Cum.t; with (b) site-1, (d) site-2, and (f) site-3.
HESSD

11, 2515-2553, 2014

A new technique using the aero-infiltrometer

M. A. Fulazzaky et al.

Title Page

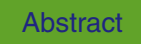

Introduction

Conclusions

References

Tables

Figures

14

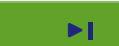

4

Back

Close

\section{Full Screen / Esc}

Printer-friendly Version

Interactive Discussion 
(a)
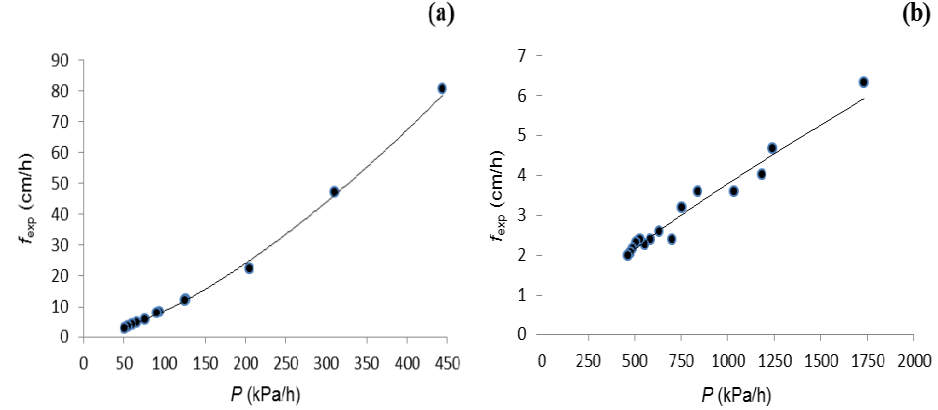

Fig. 4. Curve $f_{\text {th }}=\alpha \cdot P^{\beta}$; with (a) site-1, (b) site-2, and (c) site-3.
HESSD

11, 2515-2553, 2014

A new technique

using the

aero-infiltrometer

M. A. Fulazzaky et al.

Title Page

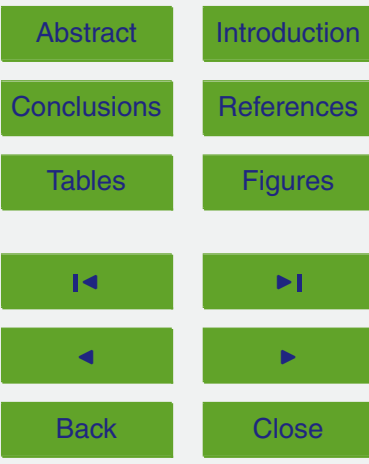

Full Screen / Esc

Printer-friendly Version

Interactive Discussion 

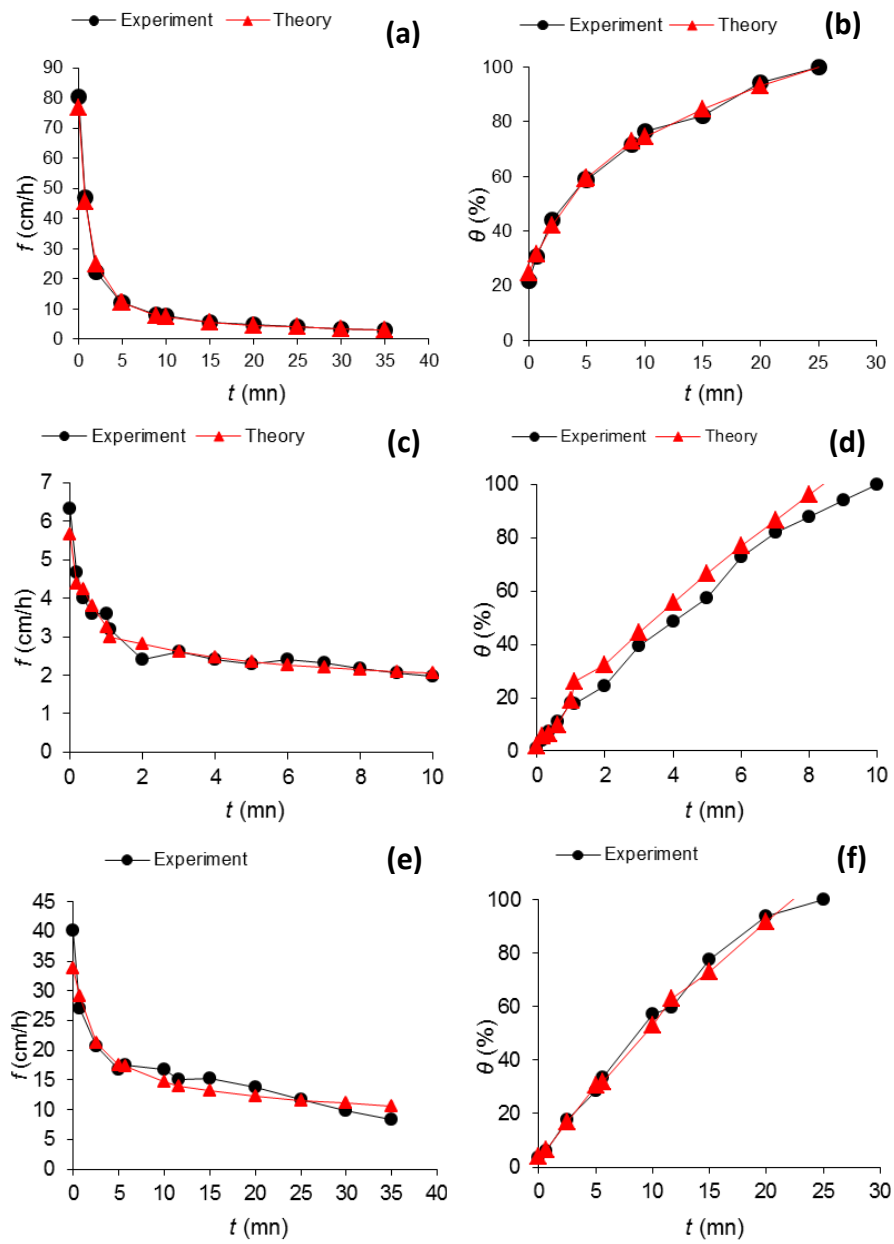

\section{HESSD}

11, 2515-2553, 2014

A new technique using the aero-infiltrometer

M. A. Fulazzaky et al.

Title Page

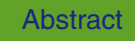

Introduction

Conclusions

References

Tables

Figures

14

4

Back

Close

\section{Full Screen / Esc}

Printer-friendly Version

Interactive Discussion

Fig. 5. Variations of $f_{\exp }$ and $f_{\text {th }}$ pursuant to $t$; with (a) site-1, (c) site-2, and (e) site-3 and variations of $\theta_{\exp }$ and $\theta_{\text {th }}$ pursuant to $t$; with (b) site-1, (d) site-2, and (f) site-3. 
(a)
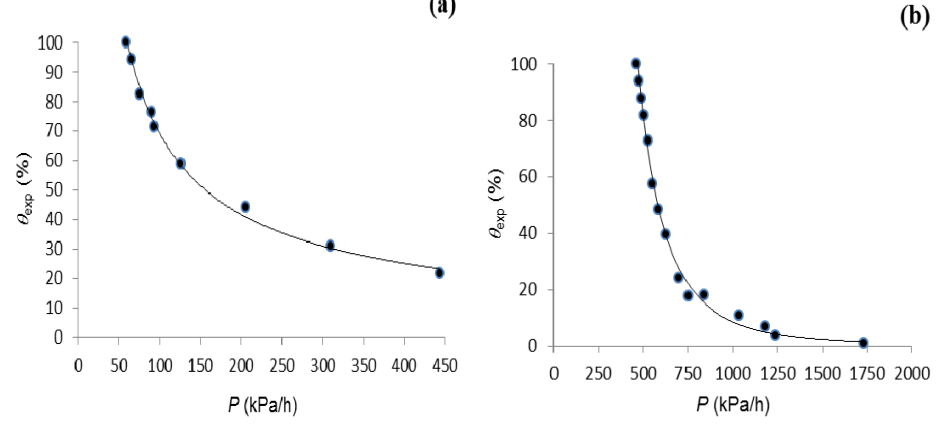

(b)

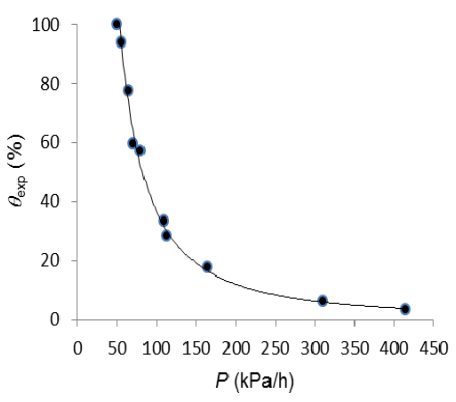

(c)

Fig. 6. Curve $\theta_{\mathrm{th}}=\varepsilon \cdot P^{\gamma}$; with (a) site-1, (b) site-2, and (c) site-3.

\section{HESSD}

11, 2515-2553, 2014

A new technique using the aero-infiltrometer

M. A. Fulazzaky et al.

Title Page

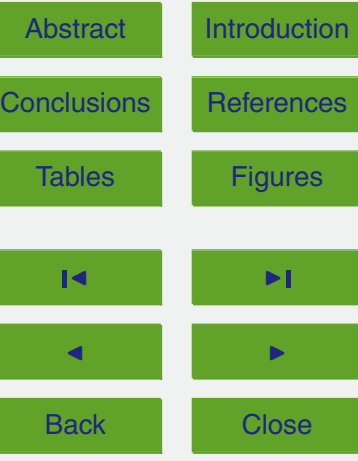

Full Screen / Esc

Printer-friendly Version

Interactive Discussion 


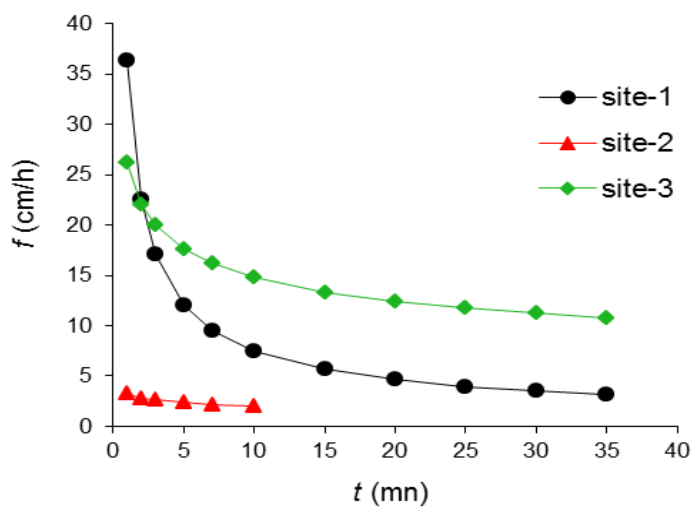

Fig. 7. Infiltration rate model of the natural soils.

\section{HESSD}

$11,2515-2553,2014$

A new technique using the aero-infiltrometer

M. A. Fulazzaky et al.

Title Page

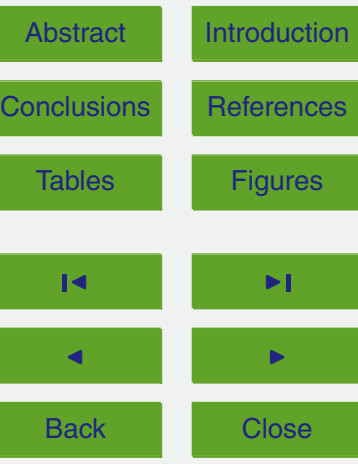

Full Screen / Esc

Printer-friendly Version

Interactive Discussion 


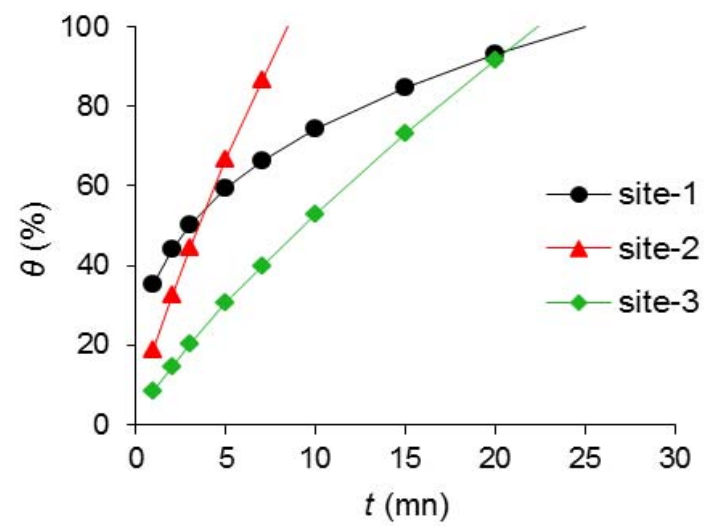

\section{HESSD}

11, 2515-2553, 2014

A new technique

using the

aero-infiltrometer

M. A. Fulazzaky et al.

Title Page

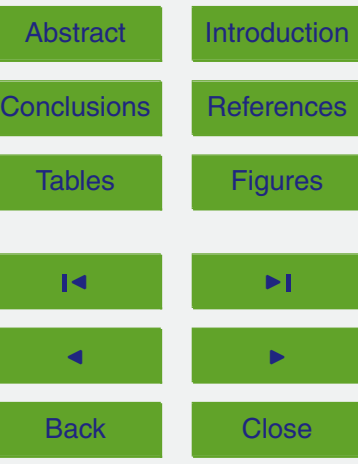

Full Screen / Esc

Printer-friendly Version

Interactive Discussion 